\title{
Streamlined Approach for Environmental \\ Restoration (SAFER): Development, Implementation, and Lessons Learned
}
J. D. Smith
J. P. Amaya

May 1994

Prepared for the U.S. Department of Energy under Contract DE-AC06-76RLO 1830

Pacific Northwest Laboratory

Operated for the U.S. Department of Energy by Battelle Memorial Institute 


\title{
DISCLAIMER
}

This report was prepared as an account of work sponsored by an agency of the United States Government. Neither the United States Government nor any agency thereof, nor Battelle Memorial Institute, nor any of their employees, makes any warranty, expressed or implied, or assumes any legal liability or responsibility for the accuracy, completeness, or usefulness of any information, apparatus, product, or process disclosed, or represents that its use would not infringe privately owned rights. Reference herein to any specific commercial product, process, or service by trade name, trademark, manufacturer, or otherwise does not necessarily constitute or imply its endorsement, recommendation, or favoring by the United States Government or any agency thereof, or Battelle Memorial institute. The views and opinions of authors expressed herein do not necessarily state or reflect those of the United States Government or any agency thereof.

\author{
PACIFIC NORTHWEST LABORATORY \\ operated by \\ BATTELLE MEMORIAL INSTITUTE \\ for the \\ UNITED STATES DEPARTMENT OF ENERGY \\ under Contract DE-ACO6-76RLO 1830
}

Printed in the United States of America

Available to DOE and DOE contractors from the

Office of Scientific and Technical Information, P.O. Box 62, Oak Ridge, TN 37831;

prices available from (615) 576-8401. FTS 626-8401.

Available to the public from the National Technical Information Service,

U.S. Department of Commerce, 5285 Port Royal Rd., Springfield, VA 22161. 
PNL-9421

UC- -402

STREAMLINED APPROACH FOR ENVIRONMENTAL

RESTORATION (SAFER): DEVELOPMENT,

IMPLEMENTATION, AND LESSONS LEARNED

J. D. Smyth

J. P. Amaya

May 1994

Prepared for

the U.S. Department of Energy

under Contract DE-AC06-76RLO 1830

Pacific Northwest Laboratory

Richland, Washington 99352

\footnotetext{
${ }^{1} \mathrm{CH}_{2} \mathrm{M} \mathrm{Hil1}$

Richland, Washington
}

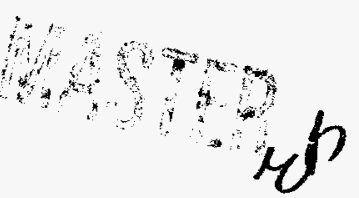



. 


\section{CONTENTS}

PREFACE. . . . . . . . . . . . . . . . . . . . . . . v v

1.0 INTRODUCTION. . . . . . . . . . . . . . . . . . . . . . . . 1

1.1 SAFER DEVELOPMENT. . . . . . . . . . . . . . . . . . . 1

1.2 SAFER TENETS . . . . . . . . . . . . . . . . . . . . 2

2.0 ACTIVITIES SUMMARY. . . . . . . . . . . . . . . . . 5

2.1 WORKSHOPS. . . . . . . . . . . . . . . . . . . 5

2.2 IMPLEMENTATION GUIDANCE/FACILITATION . . . . . . . . . . . 8

2.3 RELATED SUPPORT ACTIVITIES . . . . . . . . . . . . . . . 9

2.4 SITE TRACKING. . . . . . . . . . . . . . . . . . . . 12

3.0 LESSONS LEARNED AND RELATED ACTIVITIES. . . . . . . . . . . . . 15

3.1 WORKSHOP LESSONS/SAFER REVISIONS . . . . . . . . . . . . . 15

3.2 INTRODUCTION OF PILOT STUDIES. . . . . . . . . . . . . . 17

3.3 FISCAL YEAR 1994 FOCUS . . . . . . . . . . . . . . 18

4.0 REFERENCES. . . . . . . . . . . . . . . . . . . . . . . . 21

APPENDIX A. MEMORANDUM: IMPLEMENTATION OF STREAMLINED APPROACH FOR ENVIRONMENTAL RESTORATION . . . . . . . . . . . . . A.1

APPENDIX B. MODULE 7. SAFER . . . . . . . . . . . . . . . B. 1

\section{FIGURES}

1.1 Planning, Assessment and Selection, and Implementation. . . . . 3

2.1 Example Agenda for SAFER Workshop . . . . . . . . . . . . . . 6

\section{TABLES}

2.1 SAFER Workshops . . . . . . . . . . . . . . . . . . 7

2.2 SAFER-Related Support Activities. . . . . . . . . . . . . . 10

2.3 Site-Specific Implementation Assistance . . . . . . . . . . . 13 


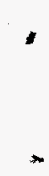




\section{PREFACE}

Environmental restoration activities required by the Comprehensive Environmental Response, Compensation, and Liability Act (CERCLA), by the Resource Conservation and Recovery Act (RCRA), or by Department of Energy (DOE) Orders are complicated and therefore time consuming. Beginning in 1989, DOE's Office of Environmental Guidance (EH-23) began to examine opportunities for streamlining the environmental restoration process through the use of the Observational Approach (OA). As a result of this examination, in early 1990, the DOE's Offices of Environmental Guidance (EH-23) and Program Support (EM43) initiated a series of jointly sponsored $O A$ workshops at various DOE operations offices. These workshops continued through the fall of 1991. The FY 1991 Observational Approach Year-End Report (Smyth, et al. 1992) describes DOE's OA activities during FY 1991.

The Pacific Northwest Laboratory (PNL) continued to provide development and implementation support to DOE's environmental restoration streamlining program. The present report summarizes DOE's activities and developments that have occurred within this effort from Fiscal Year (FY) 1992 to the present. The most significant development has been the emergence of the Streamlined Approach for Environmental Restoration (SAFER) framework, the result of integrating elements derived from both the $O A$ and the Data Quality Objectives (DQO) process that has been developed by EPA. In addition to addressing the development of the SAFER framework, this report also describes the initial implementation of SAFER at a DOE site. The report provides continuity between the application of the $O A$ and the SAFER framework by tracking progress at the sites described in the FY 1991 report and by initiating the tracking of SAFER applications. Projected future SAFER activities are also discussed in this report.

Since FY 1992, the breadth of the team providing SAFER support to the field has been expanded. Initially composed of staff from DOE, the Environmental Protection Agency (EPA), Pacific Northwest Laboratory (PNL), $\mathrm{CH}_{2} \mathrm{MH} \mathrm{Hill}$, and MAC Technical Services Company (MACTEC), the team has grown to 
include staff from Oak Ridge National Laboratory (ORNL), ICF Incorporated (ICF), and Project Performance Corp (PPC). This expansion of the SAFER support team was effected by DOE to ensure that the program continues to enjoy and benefit from fresh perspectives and enhanced group dynamics. Similarly, sponsorship of the program has also expanded and now includes EM-43, EH-23, and EM-56 (Office of Special Projects). 


\subsection{INTRODUCTION}

This report reviews the U.S. Department of Energy's (DOE's) Streamlined Approach for Environmental Restoration (SAFER) effort during FY 1992, FY 1993, and the first quarter of FY 1994. The report comprises three sections: Introduction, Activities Summary, and Lessons Learned and Related Activities. This section provides context for the report by briefly reviewing the development of SAFER and its operational assumptions. Section 2 (Activities Summary) describes SAFER workshops and site-specific SAFER implementation support. Additionally, Section 2 provides an update on the status of sites that initially received support from either Observational Approach (OA) or SAFER teams and subsequentiy implemented either of these two related approaches to site restoration streamlining. Section 3 describes lessons learned and upcoming SAFER activities.

\subsection{SAFER DEVELOPMENT}

The DOE's Offices of Program Support (EM-43), Environmental Guidance (EH-23), and Special Projects (EM-56) are jointly supporting DOE field offices in efforts to streamline the environmental restoration process. Initially, this support was provided by EH-23 and EM-43 through OA Workshops. These workshops are described in the report, Observational Approach Implementation Guidance: Year-End Report (Smyth et al. 1992). During FY 1992, the OA was merged with another streamlining approach, the Data Quality Objectives (DQO) Process, which was developed by the U.S. Environmental Protection Agency's (EPA's) Quality Assurance Management Staff (QAMS) and was initially supported by the DOE Office of Special Projects (EM-56). This synthesis of elements derived from both the $O A$ and the DQO process has been designated SAFER. DOE's activities during FY92, FY93, and the first quarter of FY94 focused on refining SAFER, communicating its principles and practices to DOE operations offices, and providing follow-on implementation assistance to several DOE facilities. 


\subsection{SAFER TENETS}

SAFER was developed to: 1) help define data sufficiency for decision making; and 2) recognize and manage uncertainty during remedial evaluation, selection, and implementation. Key tenets include:

- emphasis on planning focused on remedial action

- explicit linkage of data collection with decision-making needs

- explicit recognition and management of uncertainty through identification of probable conditions, deviations to those conditions and development of contingency plans to respond to deviations

- early definition of probable remedies

- proactive involvement of stakeholders.

SAFER is a process for making decisions in an uncertain environment (e.g., what is the probable remedy, what constitutes sufficient characterization, what is a deviation, which contingency plan should be implemented). SAFER assumes and is predicated on an iterative process that undertakes the collection of data for the purpose of site characterization and risk assessment, technology evaluation, selection, and implementation. Specifically, as shown in Figure 1.1, for DOE's environmental restoration effort, SAFER consists of three phases: planning, assessment and selection, and implementation. This alignment allows a user to demonstrate SAFER's compatibility with the Comprehensive Environmental Response, Compensation, and Liability Act (CERCLA), the Resource Conservation and Recovery Act (RCRA) corrective action process, and EPA's Superfund Accelerated Cleanup Model (SACM). Under CERCLA, these three phases are roughly equivalent to scoping, remedial investigation and feasibility study (RI/FS), and remedial design and action. Under RCRA corrective action, the phases equate to scoping, RCRA Facility Investigation, Corrective Measures Study, and Corrective Measures Implementation. SACM is part of EPA's initiative to provide a regulatory framework for accelerated cleanup opportunities. SAFER's decision-making process is compatible with SACM (e.g., emphasis on early convergence on likely remedies, when possible). 
SAFER assumes that the most successful and efficient site restorations will reflect a tailored yet flexible strategic approach. Developing such a strategic approach requires the identification of which problems at the waste site demand early actions (e.g., removal actions, interim actions) and which are most appropriately addressed through longer-term restoration approaches (e.g., RI/FS). As a decision making process, the SAFER framework is applicable to either scenario.

SAFER assumes, and was developed in response to, a recognition of the inherent uncertainty encountered during environmental restoration. This uncertainty is pervasive in that it occurs in data collection and measurement, site and contaminant characterization, risk assessment, remedial alternative selection and implementation, and regulatory requirements. SAFER was developed to respond to this uncertainty, and to provide a framework that can

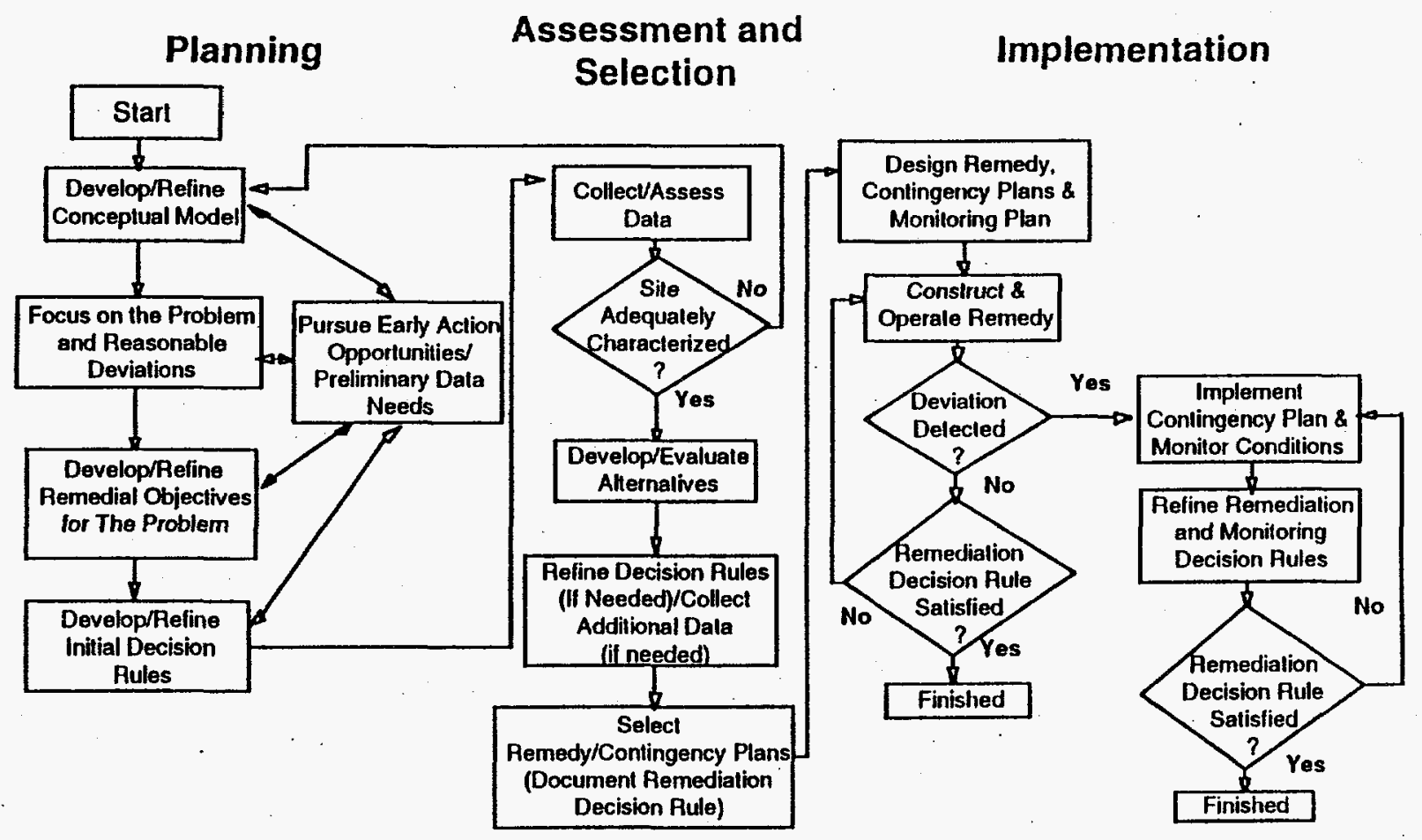

FIGURE 1.1. Planning, Assessment and Selection, and Implementation. 
be used to assist in managing uncertainty while making environmental restoration decisions.

A detailed description of SAFER concepts can be found in Gianti et al. (1993) and in the SAFER module of DOE'S RI/FS Process, Elements, and

Techniques Guidance (DOE 1993). (See Appendix B.) 


\subsection{ACTIVITIES SUMMARY}

Following SAFER's development, this year's efforts have focused on two main areas: presenting SAFER workshops and providing implementation guidance. Workshops and implementation guidance are the key tools DOE-HQ uses to provide SAFER training to the field offices. This section provides an overview of these SAFER activities.

\subsection{WORKSHOPS}

SAFER workshops were developed for the express purposes of providing an introduction to SAFER concepts and initial SAFER training. The two-day workshops consisted of the following elements: 1) a formal presentation describing the SAFER process in environmental restoration; how it can be incorporated in the CERCLA/RCRA remedial process and summaries of case histories; and 2) an informal technical session where site-specific applications of SAFER are discussed and hypothetical case studies are worked through as a group exercise. Figure 2.1 is an example agenda for the SAFER workshops. This format was developed to address a diverse audience with varying project interests, rather than a specific project team. Projectspecific support was made available for further training and site-specific facilitation following the training course.

As summarized in Table 2.1, SAFER workshops were presented for the following organizations during the past two years: Westinghouse Electric Corporation Government Contractors, the Uranium Mills Tailings Remedial Action (UMTRA) Program Office, the Formerly Utilized Site Remedial Action Project (FUSRAP) Program Office, the Rocky Flats Operations Office, the San Francisco Operations Office, the Savannah River Operations Office, the Albuquerque Operations Office, the Richland Operations Office, and the Nevada Operations office. The Westinghouse workshop targeted senior Westinghouse staff at DOE facilities managed by Westinghouse. In addition to Westinghouse corporate staff, personnel attended from Hanford, Fernald, Idaho National Engineering Laboratory (INEL), Savannah River, and the Waste Isolation Pilot Project 


\section{SAFER Workshop Agenda \\ Albuquerque, NM \\ July 22-23, 1992}

$\underline{\text { Day } 1}$

8:00 Introductory Remarks/Course Overview

Rich Dailey

8:20 Case Study: Background Briefing

Kevin Hull

8:40 SAFER Planning Discussion

Kevin Hull

9:40 BREAK

10:00 Case Study Exercise (Pt. 1)

12:00 LUNCH

1:00 Case Study Exercise (Pt. 2)

2:00 SAFER Assessment/Selection Discussion

Sam Gianti

2:45 BREAK

3:00 SAFER Implementation Discussion

Jeff Smyth

3:45 Day 1 Summary

4:00 ADJOURN

Day 2

8:00 Day 2 Overview

8:30 Case Study Exercise (Pt. 3)

10:00 BREAK

10:15 Facility-Specific Site: Overview and Discussion of Conceptual Model

11:30 LUNCH

1:00 Facility-Specific Site: Discussion of Planning Issues

2:30 BREAK

2:45 Facility-Specific Site: Continuation of Planning Discussion

4:00 SAFER Pilot Discussion and Close-Out

\section{FIGURE 2.1. Example Agenda for SAFER Workshop}


TABLE 2.1. SAFER Workshops

\begin{tabular}{|l|l|l||}
\hline \multicolumn{1}{|c|}{ Organization } & \multicolumn{1}{|c|}{ Date } & \multicolumn{1}{|c|}{ Follow-on Support } \\
\hline Westinghouse Electric Co. Government Contractors & February 19/20,1992 & More workshops requested \\
\hline UMTRA Program Office & March 25/26, 1992 & No \\
\hline FUSRAP Program Office & June 10/11, 1992 & Ventron Site Work Plan \\
\hline Rocky Flats Field Office & October 29/30,1992 & No \\
\hline San Francisco Operations Office & April 13, 1993 & No \\
\hline Savannah River Operations Office & May 17/18, 1993 & No \\
\hline Albuquerque Operations Office & July 22/23, 1993 & LANL MDA P Review/Mound \\
\hline Richland Operations Office & & Review \\
\hline Nevada Test Site & September 14/15, 1993 & No \\
\hline
\end{tabular}

(WIPP). Additional training sessions have been requested from some of these sites as a result of this workshop.

Workshops provided to the UMTRA and FUSRAP Program Offices presented the first opportunity to examine the application of SAFER principles to the unique regulatory frameworks under which these programs operate. Follow-on support was requested and provided to the FUSRAP program in the development of a work plan for the Ventron Site in Beverly, Massachusetts.

The Rocky Flats workshop was attended by contractor and DOE staff, as we11 as by representatives of the Colorado Department of Health and the U.S. EPA Region VIII Federal Facility staff. As a result of the workshop, DOE staff at Rocky Flats have endorsed SAFER and encouraged its use at the site (in EPA's Superfund Report, 1992). The UMTRA Workshop was also attended by Colorado Department of Health Staff.

The Savannah River workshop was attended by DOE and contractor staff, representatives of the State of South Carolina and EPA Region IV, and representatives of the Weldon Spring site. Representatives of EPA and the 
State of South Carolina were very impressed with the emphasis the SAFER process gives to stakeholder participation.

The Albuquerque workshop was attended by DOE and contractor staff from Albuquerque, Mound, Pantex, Pinellas, Sandia, Los Alamos, and Headquarters, as well as representatives from the State of New Mexico and EPA Region VI. Follow-on assistance was requested and provided to LANL and Mound as a result of this workshop.

The Richland workshop was attended by DOE and contractor staff from Hanford, Nevada Operations Office, Washington State Department of Ecology, and EPA Region X. As a result of the Richland workshop, a presentation was also requested for decision-makers from DOE and the regulators at Nevada Test Site.

\subsection{IMPLEMENTATION GUIDANCE/FACILITATION}

Implementation guidance/facilitation is provided to specific groups who request follow-on support to incorporate SAFER in environmental restoration activities following a workshop. One group that received a workshop requested follow-on support: the FUSRAP program's Ventron Site in Beverly, Massachusetts. Frequently, following the training workshops listed in Table 2.1, staff have requested additional workshops (e.g., Hanford, Pantex, Savannah River). Site-specific implementation guidance and facilitation will follow these on-site training sessions.

The follow-on support provided to the FUSRAP program was an outgrowth of the FUSRAP SAFER Workshop held in Oak Ridge, Tennessee in June 1992. This provided the first opportunity to apply SAFER to the FUSRAP Program's regulatory framework. The impetus for requesting this support was a desire to significantly reduce the sampling effort called for in earlier drafts of the site characterization report.

Working closely with the FUSRAP contractor staff, SAFER was adapted to both the FUSRAP regulatory framework and to meet the site-specific technical requirements for characterization plan development. This relates basically to moving through the SAFER planning segment of Figure 1.1. The workplan 
received extremely positive reviews and, in fact, did result in initial sampling requirements being reduced, relative to earlier drafts. During the development of the characterization plan, the FUSRAP contractors and program office developed an understanding that SAFER offered many advantages in addition to the potential to reduce sampling. The advantages the FUSRAP team found include:

- integrating data collection and its uses

- developing decision rules to define data sufficiency and the follow-on action

- understanding the use of the conceptual model as a working tool to represent expected conditions and deviations

- using risk assessment information as an integral part of developing decision rules.

A visit to the Mound Facility took place on November 2-3, 1993 as a follow-on to the SAFER workshop held in Albuquerque, July 22-23, 1993. The majority of the visit focused on a review of the Building B Storage Shed Interim Response Action (IRA). A number of suggestions were provided aimed at accelerating initiation of the IRA and for managing the technical uncertainties associated with the response action.

Follow-on assistance was also provided to LANL as a result of the Albuquerque workshop. A review was conducted of the Closure and Post-Closure Plan for MDA-P. Comments were provided based on a review of the plan from a "SAFER application" standpoint. The comments were provided to illustrate some areas where the current plan could be modified to better track with the SAFER framework.

\subsection{RELATED SUPPORT ACTIVITIES}

As a part of this project, various SAFER-related activities are also conducted. These activities are often an outgrowth of the desire of DOE to increase SAFER's visibility; therefore, they focus on presentations and 
IABLE 2.2. SAFER-Related Support Activities

\begin{tabular}{|l|l|l||}
\hline \multicolumn{1}{|c|}{ Event } & \multicolumn{1}{|c|}{ SAFER Activity Description } & Date \\
\hline $\begin{array}{l}\text { Department of Energy } \\
\text { Headquarters Presentation }\end{array}$ & Provided briefing to DOE-HQ staff on SAFER & January 28, 1992 \\
\hline Train-the-Trainers Course & $\begin{array}{l}\text { Provided initial course to potential trainers in an } \\
\text { effort to expand HQ support team }\end{array}$ & June 23-25, 1992 \\
\hline $\begin{array}{l}1992 \text { Environmental Science } \\
\text { and Waste Management } \\
\text { Conference }\end{array}$ & $\begin{array}{l}\text { Developed paper and presentation entitled "SAFER: An } \\
\text { Overview" }\end{array}$ & April 9-11, 1992 \\
\hline $\begin{array}{l}\text { Westinghouse Government } \\
\text { Contractors Presidents } \\
\text { Conference }\end{array}$ & $\begin{array}{l}\text { Provided SAFER presentation to senior staff from } \\
\text { Westinghouse Electric Corporation }\end{array}$ & March 16,1992 \\
\hline $\begin{array}{l}\text { EPA/DOE Pilot Studies } \\
\text { Agreement }\end{array}$ & $\begin{array}{l}\text { Proposed to conduct joint pilot studies with EPA of } \\
\text { SAFER application at selected DOE facilities }\end{array}$ & July 29, 1992 \\
\hline $\begin{array}{l}\text { Rocky Flats Operable Unit } 2 \\
\text { Work Plan Review }\end{array}$ & $\begin{array}{l}\text { Reviewed treatability study work plan for } \\
\text { incorporation of OA }\end{array}$ & January 1992 \\
\hline $\begin{array}{l}\text { Pilot Study Development } \\
\text { Initiated development of pilot site selection } \\
\text { criteria and measures of success }\end{array}$ & July 1993 \\
\hline SAFER module & $\begin{array}{l}\text { Developed SAFER module for use in DoE's RI/FS Guide } \\
\text { November } 1993\end{array}$ \\
\hline
\end{tabular}

conferences. Since FY 1992, five main support activities were conducted by DOE. These activities included: 1) providing a SAFER Train-the-Trainers course; 2) developing a SAFER conference proceedings paper and presentation; 3) providing a SAFER presentation to Westinghouse Electric Corporation Government Contractors senior staff; 4) development of the SAFER pilot Study process; and 5) development of the SAFER module for DOE's RI/FS Process, Elements, and Techniques Guidance document. These and other activities are summarized in Table 2.2.

The SAFER Train-the-Trainers workshop was held to initiate the expansion of the HQ support team. The course was designed to provide initial training and information to selected DOE and contractor staff. Specifically, the objectives of the Train-the-Trainers workshop were to:

- communicate the objectives, strategy, and status of the SAFER effort

- bring participants up to speed on the content of SAFER

- share techniques for successful SAFER training, including general "how to train" tips as well as advice specifically focused on the SAFER course 
- share techniques for facilitating SAFER implementation at DOE sites (both as training case studies and as "real life" interventions)

- identify, from workshop participants, appropriate staff for further training and integration into the HQ SAFER team.

As additional SAFER workshops are scheduled and given, it is anticipated that new staff will be integrated into the SAFER team.

Other activities included presentations of SAFER concepts. One presentation included the development of the paper entitled "Streamlining Approach for Environmental Restoration (SAFER): An Overview" (Dailey et al. 1992) and the companion presentation for the 1992 Waste Management and Environmental Sciences Conference in San Juan, Puerto Rico, on April 9-11, 1992. The Dailey et al. paper has since been distributed as part of the SAFER workshops and to DOE staff requesting more information on SAFER. Additionally, a SAFER presentation was requested and given to Westinghouse Electric Corporation senior staff at their annual Presidents Conference. A presentation was also given to DOE-HQ to brief them on SAFER.

The SAFER team also had the opportunity to review the Rocky Flats Operable Unit 2, December 23, 1991 "Preliminary Draft Proposed Subsurface Interim Measures/Interim Remedial Action Plan/Environmental Assessment (IM/IRAP/EA) and Decision Document," and comment on their incorporation of the OA element of SAFER. This activity resulted from FY 1991 efforts.

The most potentially significant of the related activities included DOE's proposal to conduct joint SAFER pilot studies with EPA at selected DOE facilities. The concept as proposed would include the use of the HQ SAFER team to provide support and assistance to DOE and its contractors in applying SAFER. EPA would be included (as would other key groups) as stakeholders to help focus decisions. EPA replied by accepting the DOE proposal on the condition that DOE "...designate a 'stakeholder decision team' that would be responsible for most, if not all of the decisions and deliverables at a site...." Further details of the pilot studies are discussed in Section 3.2 . 
Finally, DOE issued the document RI/FS Process, Elements, and Techniques Guidance. This guidance thoroughily integrates SAFER into the RI/FS process, provides a stand-alone module describing SAFER, and presents two case studies which utilized SAFER's parent methodologies to achieve streamlining. DOE plans to develop companion RD/RA guidance also thoroughly integrating SAFER.

\subsection{SITE TRACKING}

We have periodically tracked and documented the use of the SAFER process, specifically the $O A$ aspects at the DOE sites where implementation guidance has been provided. The opportunity to track facilities' activities provides a record of experience that can be used both in future applications and as a history of SAFER applications in the remedial process. The application history can be used as a means of effectively communicating to regulators a method that was used to streamline the environmental restoration process. Equally important, however, is the documentation of how nontechnical considerations (i.e., political drivers, or the unrealistic belief that complete knowledge of site characteristics can and should exist before remedial actions begin) might circumvent the benefit of using the SAFER framework. Table 2.3 provides details on specific assistance provided to facilities and their status. 
TABLE 2.3. Site-Specific Implementation Assistance

\begin{tabular}{|c|c|c|c|c|c|}
\hline Facility & Site & $\begin{array}{l}\text { Regulatory } \\
\text { Framework }\end{array}$ & Objective & Product & Status \\
\hline LANL & Site-wide & $\begin{array}{l}\text { RCRA, corrective } \\
\text { action }\end{array}$ & $\begin{array}{l}\text { Develop example streaml ining } \\
\text { strategy }\end{array}$ & $\begin{array}{l}\text { Appendix in Site-Hide } \\
\text { Workplan }\end{array}$ & $\begin{array}{l}\text { Workplan received tentative } \\
\text { approval from EPA Region } \\
\text { VI: currently revising } \\
\text { site-wide Workplan } \\
\end{array}$ \\
\hline ORNL & $\begin{array}{l}\text { Waste Area Grouping } \\
5\end{array}$ & CERCLA & $\begin{array}{l}\text { Developed RI/FS streaml ining } \\
\text { strategy }\end{array}$ & $\begin{array}{l}\text { Presentation to DOE-OR } \\
\text { and regulators } \\
\text { responsible for workplan } \\
\text { approval }\end{array}$ & $\begin{array}{l}\text { Strategy Received } \\
\text { endorsement from EPA Region } \\
\text { IV, Tennessee regulators. } \\
\text { and DOE-OR }\end{array}$ \\
\hline SNL & Technical Area 2 & $\begin{array}{l}\text { RCRA, corrective } \\
\text { action }\end{array}$ & $\begin{array}{l}\text { Supplement existing interim } \\
\text { workplan with streaml ining } \\
\text { strategy }\end{array}$ & $\begin{array}{l}\text { Strategy outline; } \\
\text { identify data needs }\end{array}$ & Interim Workplan proceeding \\
\hline FUSRAP & $\begin{array}{l}\text { Yentron- Beverfy, } \\
\text { hassachusetts }\end{array}$ & & $\begin{array}{l}\text { Integrate saFER cancepts in } \\
\text { the charicterization plan } \\
\text { developatent }\end{array}$ & Sampling plan & $\begin{array}{l}\text { Characterization plan } \\
\text { devetoped }\end{array}$ \\
\hline LANL II & MDA P & RCRA & $\begin{array}{l}\text { Integrazing SAFER } \text { onto } \\
\text { closure post closure plat }\end{array}$ & Revitew & \\
\hline MOÜB & of $1,4,9$ & CERCLA & Integrating SAFER into IRA & Rectimendat ions for saH & SOH an developmont \\
\hline
\end{tabular}

*NOFE - Shaded areas are specifäc to FY 1992 m93 work. 


\subsection{LESSONS LEARNED AND RELATED ACTIVITIES}

This section provides an overview of other activities that have been conducted to both enhance SAFER and assist field offices with training and implementation. The pilot studies, first introduced in Section 2, are also discussed in greater detail. Many of these activities resulted from experience gained while conducting this year's SAFER workshops.

\subsection{WORKSHOP LESSONS/SAFER REVISIONS}

Feedback has been received on the perceived strengths and weaknesses of SAFER. The workshop evolved and progressed with each presentation. Both experience gained and evaluations from workshop participants highlighted areas where improvements could be made. To address these areas, the DOE-HQ support team convened on December 1-2, 1992 to discuss possible revisions to SAFER. The revisions discussed and modifications effected included:

- Balance Planning, Assessment and Selection, and Implementation Sections of SAFER Presentation. The planning segment of SAFER was disproportionately detailed relative to the other portions of the remedial process. However, elements of planning, such as the decision rule, were not being effectively communicated. To address these concerns, the SAFER team enhanced the assessment and selection and implementation sections by integrating relevant issues and providing increased detail on monitoring and contracting. Additionally, a case study was adopted from the DOE RI/FS course to help demonstrate the development and use of decision rules and assessment and selection in SAFER. The case study was also developed to clarify the development of contingency plans and to consider monitoring issues.

- Presenting Balance Between Focus and Flexibility. SAFER emphasizes focusing on the most likely problem based on probable conditions. The reasoning behind this focus is to reduce data collection efforts. Further, the focus encourages establishing quantitative remedial action objectives (RAOs) early in the process and aggressively screening 
unlikely remedial alternatives. Even though they are termed preliminary; quantitative RAOs tend to drive the remedial process. This, in actuality, is the goal of focusing: the more definitive the goal can be stated, the better the ability to identify appropriate data needs, likely alternatives, and deviations. This perspective is constructive as long as the problems at a site are understood sufficiently to correctly define probable conditions at an early point in the process. However, operating concurrently with the emphasis on focusing is the desire within SAFER to preserve flexibility. The flexibility must be sufficient to respond to uncertainties inherent in waste site remediation. In the DOE arena, characterization issues are often not well understood and alternatives are limited. Precisely because quantitative RAOs will drive the remedial process, there is concern that if flexibility is not maintained all alternative screening and evaluation will, in fact, be performed. Moreover, DOE could easily be driven to a worst-case scenario by using conservative quantitative numbers and by establishing an aggressive focus. The alternative selection may be performed based on one criterion (i.e., estimate of what constitutes protection of human health and the environment.

The SAFER team agreed that the workshop presentation must present a balanced view of encouraging focus and maintaining flexibility. The method of communicating this is to explain how SAFER is adaptable to either and under what conditions one may be more advantageous than the other.

- Stakeholder Consensus. The concept of stakeholder consensus, as it has been described and presented at SAFER workshops, is not seen by stakeholders as what typically occurs at many DOE facilities. The reality is often that the project team will develop a single stakeholder's preferred strategy (DOE's) and then it will be used in negotiations among other stakeholders.

The SAFER team discussed whether the presentation should be changed to reflect actual experience, or remain as an ideal concept and the 
reality discussed. Based upon the additional recognition that the SAFER pilot studies would strive for the ideal concept of forming a stakeholder decision team, it was decided that the concept was adequately presented. Further, that at a minimum, encouraging and considering the stakeholders' perspectives, regardless of whether consensus can be negotiated, added value to developing workplans and other compliance documentation.

- Communicating Applicability of SAFER to Early Action/SACM. EPA's recent emphasis of SACM and the advantages of interim actions are creating good opportunities to help streamline environmental restoration. SAFER is equally applicable and adaptable to remedial approaches outlined by SACM, interim actions, or full-scale remedial actions. The SAFER team decided to emphasize and communicate the concept of SAFER's applicability and adaptability during the workshop. The means of doing this included making revisions to the SAFER framework to explicitly identify early action opportunities and demonstrating how SAFER might be adapted to a removal action in a case study.

\subsection{INTRODUCTION OF PILOT STUDIES}

EPA has found the remedial process to be very time consuming and has expressed an interest in collaborating with DOE in the development of joint SAFER pilot studies. The purpose of the studies would be to implement SAFER and to assist selected sites from "cradle to grave" in their environmental restoration efforts. Such interagency sponsorship offers an excellent opportunity to advance both the visibility and the credibility of the SAFER framework.

The concept of joint SAFER pilot studies has been discussed throughout FY 1993 and was specifically addressed at meetings between DOE staff and representatives of EPA's Superfund Revitalization Office and Office of Federal Facilities Enforcement. EPA has responded favorably to a DOE-HQ memorandum requesting their formal participation in conducting the pilot studies and has 
since distributed a memo to the regions announcing the pilot studies (see Appendix A).

Site selection activities for the pilot studies have been initiated. It is currently envisioned that four sub-projects will be selected from those facilities that nominate candidate sites for the pilot studies. While the details on the level of support provided to the sites has not been fully determined, it is expected to include a full SAFER presentation and workshop, as well as follow-on implementation support. This support will include assistance to the facility in coordinating and implementing SAFER. The potential benefits to DOE facilities for their participation in the pilot studies include the opportunity for the movement of decision-making authority to the field and an opportunity to demonstrate progress to the public.

Specific activities relative to implementing the joint pilot studies include: 1) revising the SAFER framework and slides, 2) holding a SAFER workshop involving EPA regional and DOE field office decision-making staff, 3) nominating and selecting pilot study host sites, 4) selecting decision-making teams for each site, and 5) providing implementation assistance at pilot study host sites.

\subsection{FISCAL YEAR 1994 FOCUS}

While the focus of fiscal year 1994 efforts will be on the development and implementation of the joint pilot studies, SAFER workshops will continue to be provided to specific sites, as requested. In addition, because the pilot studies will only be available to CERCLA sites, it is anticipated that follow-on implementation guidance will continue at RCRA sites. Other activities anticipated to be conducted during the fiscal year include:

- Assist DOE in establishing a framework for measuring success of the SAFER Pilot Projects, specific goals that the SAFER Pilot Projects will attempt to achieve, baselines against which progress will be measured, and a system to report success as the pilot projects occur. 
- Assist DOE in tracking the use of SAFER at DOE sites where guidance is provided. The tracking of site activities provides a record of experience that can be used both in future applications and as a history of SAFER applications in the remedial process. The application history can be used as a means of effectively communicating to regulators a method that was used to streamline the environmental restoration process.

- Assist DOE in the development of a journal article detailing the technical aspects of SAFER. 
. 


\subsection{REFERENCES}

Blacker, S., and K. Hul1. 1990. "Applying Total Quality Principles to Superfund Planning." Presented at the 17th Annual National Energy Division Conference, American Society for Quality Control.

Dailey, R., D. Lillian, and D. Smith. 1992. "Streamlining Approach for Environmental Restoration (SAFER): An Overview." Presented at Waste Management and Environmental Sciences Conference, San Juan, Puerto Rico, Apri 1 9-11.

Gianti, S., R. Dailey, K. Hull, and J. Smyth. 1993. "The Streamlined Approach to Environmental Restoration." In Proceedings of Waste Management 1993, Vol. I, p. 585. Tucson, Arizona.

Hendrickson, P. L. 1993. U.S. Department of Energy Orders With the Potential to Inhibit Environmental Remediation Activities at DOE Sites. PNL-8474, Pacific Northwest Laboratory, Richland, Washington.

Holm, L. A. 1993. "Remedial Strategies." Chapter 14 in Geotechnical Practice For Waste Disposal, ed. D. E. Daniel. Chapman Hal1, London.

Hu11, K., and D. Neptune. 1991. "The Data Quality Objective Process." Journal for Quality and Participation, September:72-78.

Ryti, R. and D. Neptune. 1991. "Planning Issues for Superfund Site Remediation." Hazardous Materials Contro7, 4:47-53.

Peck, R. B. 1969. "Advantages and Limitations of the Observational Method in Applied Soil Mechanics." Geotechnique 19(2):171-187.

Smyth, J., J. Kohlman, and M. Peffers. 1992. Observational Approach Implementation Guidance: Year-End Report. PNL-7999, Pacific Northwest Laboratory, Richland, Washington. 
APPENDIX A

MEMORANDUM: IMPLEMENTATION OF STREAMLINED APPROACH FOR ENVIRONMENTAL RESTORATION 


\section{UNITED STATES ENYIRONMENTAL PAOTECTION AGENCY}

WASHINGTON, D.C. 20450

$$
\text { SEP - } 31993
$$

OFFIEE OFENFOFCEMENT

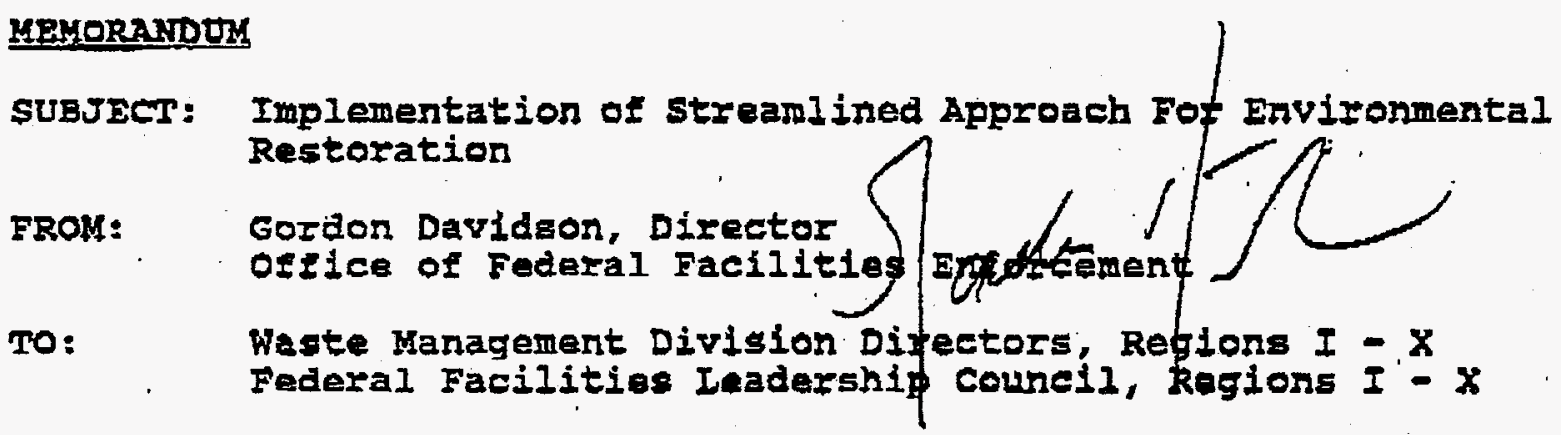

As part of the Administrative Fixes, we are encouraging Regions to pliot the Department of Energy's (DOE) approaeh to accelerated cleanup known as Streamlined Approach for Environmental Restoration (SAFER), We have been engaged in discussions with DOI during the past year to address several concerns that the federal Facilities Ieadership council (FFLC) raised, especially state participation. DOE has made modifications to its SAFER pilot project proposal to incorporate changes that promote public and state participation and delegate decision authority to the field. EPA and DOE believe we are now at a point to conduct several SAFER pilots. To assist with implementation of the SAFER pliots, the office of Federal Facilities Enforcement (OFFI) can provide up to $\$ 100,000$ in extramural Eunding this year.

The main responsibility for implementing the SAFER pllots will be in the Regional progran offices. Candidate sites should be norinated jolntly by EPA Regional offlees, statos and Dos through the suparfund Accelerated Clean-up Model (SACM) pilot project process, oFfe will monitor the aceeleration pilots on a quarterly basis. If you heve any questions about the acceleration policy of SAFER, plasse contact Jim Foolford, BPA, at (207) 260-1606 or Rich Dailey, DOE, at (202) 586-7117.

ce: Tad MaCal1, Ir., OFFE

Tin Fielda, SRO

Martha steincamp, ORC Region VII

Jim Woolford, OFFE

Ray Berube, DOD

Pat Whitfield, DOE

Rich Dailey, DOE

A. 1 
APPENDIX B

MODULE 7. SAFER 
Module 7

Streamlined Approach For Environmental Restoration

Contents

Page

$\begin{array}{lll}7.1 & \text { SAFER Introduction } & \mathbf{7 - 7}\end{array}$

7.2 SAFER During Scoping and Remedial Investigation/Feasibility Study $\quad \mathbf{7 - 2 1}$

7.3 SAFER During Remedial Design and Remedial Action $\quad$ 7-39

B. 1 


\section{From:}

- Petinninarj Assessmeni

- HRS Evaivätion

- Stte Inscestict

- Hyjpl. Listung
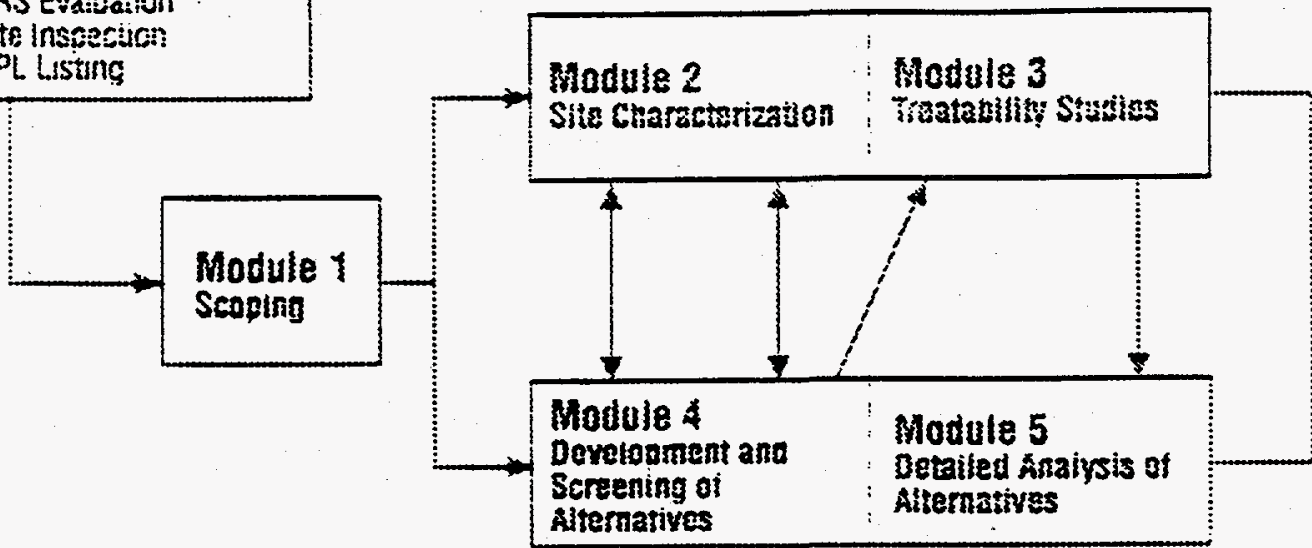

Module 6

femsay

Salection anu

Dosumontation:

Module 4

Screening o:

Betailed Anaiysis of

Aiternatiyes

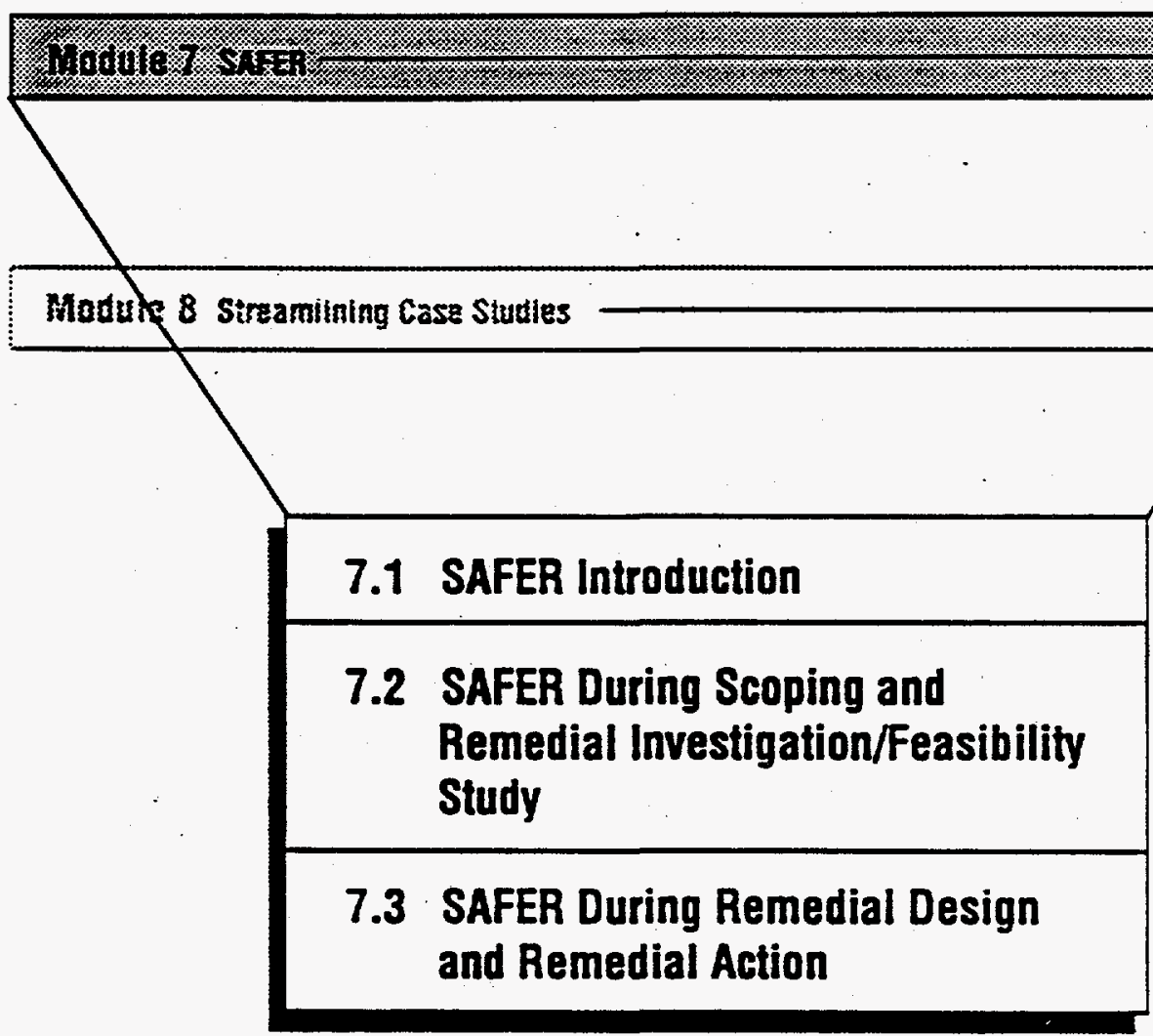

Module 7. SAFER 
Module 7

Streamlined Approach For Environmental Restoration

\section{Backgroused}

The Deparment of Energy (DOE) developed the Streamlined Approach For Environmental Restoration (SAFER) as a methodology tailored to the challenges of conducting environmental restoration effors under conditions of significant uncertainty. SAFER was developed primarily by integrating the data quality objectives (DQOs) process with the observational approach. The intent of this effor was to provide a consistent and comprehensive streamiining approach that illustrated the collaborative benefits of the two approaches.

SAFER is based on the need. from both a scientific and engineering perspective. to make decisions under uncertain conditions while maintaining progress throughout the environmental restoration process. SAFER is derived from approaches originally used in environmental quality assurance (Blacker et al.. 1990) and geotechnical engineering (Peck. 1969). (Furiher information on these approaches can be found by consulting the Sources.) To further facilitate progress, DOE also recognized the need to involve groups with vested interests (e.g., regulators. Native Americans) in environmental restoration activities into each step of an environmental restoration project. and thus incorporate frequent. significant input from stakehoiders as a major element of SAFER.

Developed for DOE's environmental restoration effor. SAFER was designed to be aggressive, yet compatible and compliant with existing environmental regulations [e.g., Comprehensive Environmental Response, Compensation, and Liability Act (CERCLA), Resource Conservation and Recovery Act (RCRA)].

\section{Integration with the RI/FS Process}

In this guidance. SAFER is a methodology used to help streamline the Remedial Investigation/Feasibility Study (RI/FS) process and to manage changes to the selected remedy. As such. SAFER concepts have been thoroughly integrated into the previous six moduies that provide guidance on conducting the RI/FS and remedy seiection process. The RI/FS and remedy selection process modules do not explicitly identify or distinguish the SAFER concepts that are used. They are presented as DOE intends to use them-as an integral part of the environmental restoration process.

This module does not repeat the process guidance provided in the first six modules: it identifies and discusses the major elements of SAFER used during an RI/FS and remedy selection. However. SAFER also is applicable as a streamlining methodology throughout Remedial Design/Remedial Action (RD/RA). This module identifies and discusses major elements of SAFER used during RD/RA. Although guidance on conducting the RD/RA process is not a part of the guidance in the earlier modules of this document, the SAFER techniques used during RD/RA are provided in this module to ensure a comprehensive understanding of SAFER's full capability for identifying and managing uncerainty throughout the environmental restoration process.

\section{Organization}

Module 7 is divided into three submodules

7.1 SAFER Introduction

7.2 SAFER During Scoping and Remedial Investigarion/Feasibility Srudy

7.3 SAFER During Remedial Design and Remedial Action 


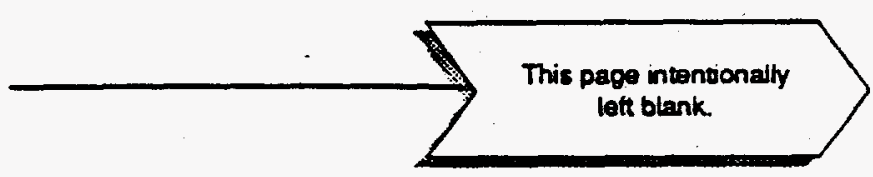

$7-4$

B. 4 
Module 7 Streamlined Approach For Environmental Restoration (continued)

The format of Module 7 is different from the first six process modules - it does not follow a graphical. flowchar process. Module 7 is divided into three submodules that provide text and companion figures to identify and discuss SAFER's main elements. This module provides an understaniding of the major SAFER elements and the role they play in each phase of the CERCLA process.

\section{Sources}

1. Blacker. S.. D. Neptune. B. Fairiess. and R. Ryti. September 1990. "Applying Total Quality Principles to Superrind Planning," in Proceedings of the 17 th Annual National Energy Division Conference. American Socierv for Quality Control.

2. Dailey, R.. D. Lillian. and D. Smith, 1992. "Streamined Approach for Environmental Restoration (SAFER): An Overview." in Proceedings of the 1992 Waste Management and Environmental Sciences Conference, April 9-11. 1992. San Juan. Pueno Rico.

3. Gianti. S., R. Dailey, K. Hull. and J. Smyth. 1993. "The Streamiined Approach For Environmental Restoration." in Proceedings for Waste Management 1993. Vol. 1. p. $585 \mathrm{ff}$.

4. Hull. K.. and D. Neprune. September 1991, "The Data Quality Objective Process," Joumal for Quality and Participation. pp. 72-78.

5. Peck, R. B, 1969. Ninth Rankine Lecture-"Advantages and Limitations of the Observational Method in Applied Soil Mechanics." Geotechnique 19. No. 2, pp. 171-87.

6. Smyth. J. D.. J. P. Amaya, and M. S. Peffers. 1992. "DOE Developments. Observational Approach implementation at DOE Facilities." in Federal Facilities Environmental Joumal, Aurumn. pp. 345-355.

7. U.S. EPA. 1990. Total Quality Management (TQM) and Qualion Assurance (QA) in Superfund. OSWER Directive 9242.6-08.

8. U.S. EPA. April 1990. Interm Final Guidance on EPA Oversight of Remedial Designs and Remedial Actions Performed by Porentiallv Responsible Panies. EPA 540/G-90/001. OSWER Directive 9355.5-01.

9. U.S. EPA. June 1992. Remedial Action Reporn: Documentation for Operable Unit Completion. OSWER Directive 9355.0-39FS.

10. Wallace, W. A., 1988, "Engineering Under Uncertainty: A New Perspective on the Cleanup of Hazardous Waste Sites." presented at Joint CSCE-ASCE National Conference of Environmental Engineering, Vancouver, B.C., Canada.

11. Wallace. W. A., 1991, "New Paradigms for Hazardous Waste Engineering," Remediation. Autumn, pp. $419-445$. 

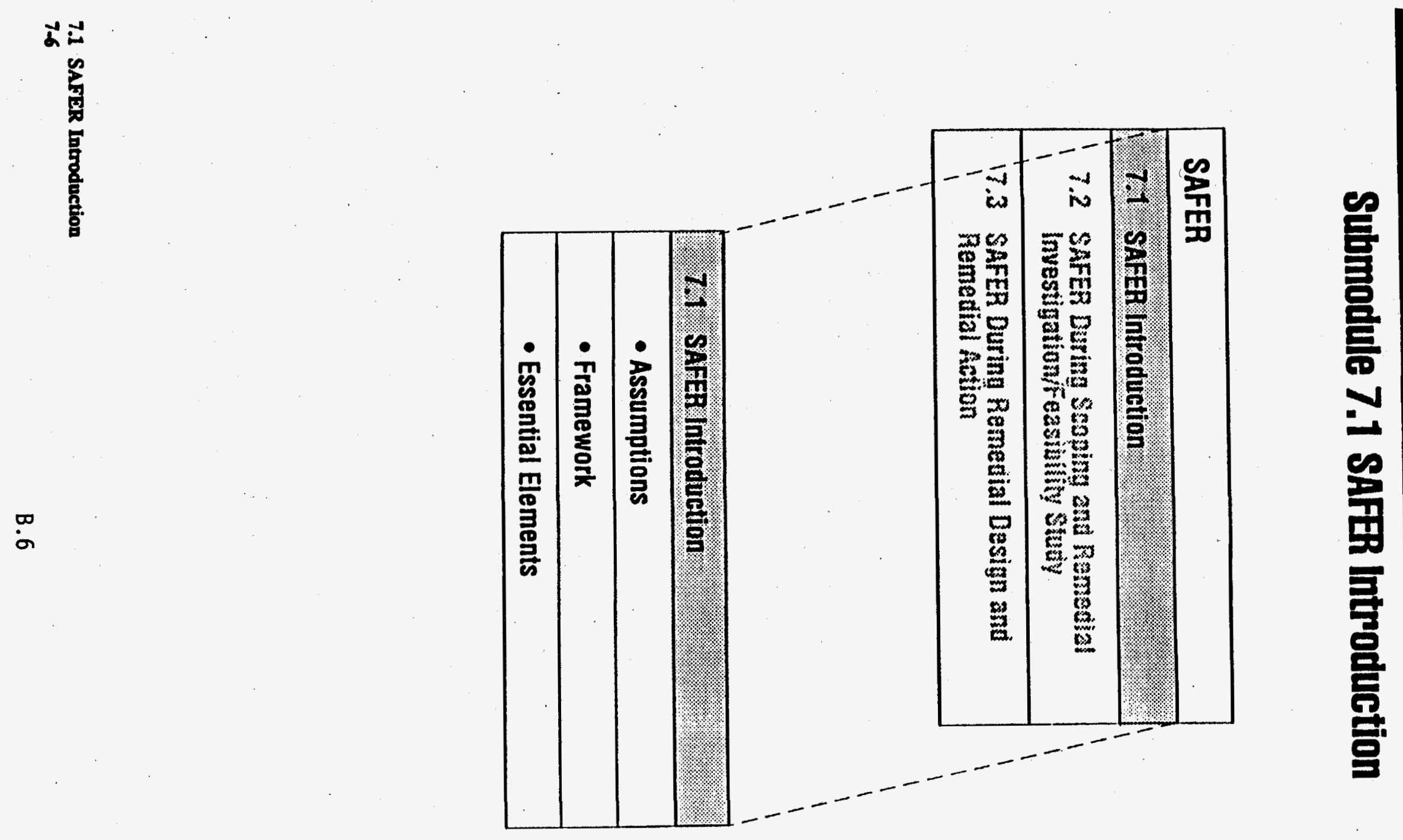


\section{Submodule 7.1 SAFER Introduction}

\section{Background}

The underiying assumption in SAFER is that inherent uncerainty will always be a factor in environmental restoration activities. SAFER groups environmental restoration uncertainry into three broad areas: site conditions, remedial technology pertiormance. and regulatory requirements. To be effective. the CERCLA process must develop and implement solutions that address waste-site problems while managing these uncertainties.

The process of developing and implementing solutions. and managing uncerainty is dependent on the environmental data measurement system. Uncerainty in data collection and evaluation is associated with any measurement system.

The uncertainty associated with the measurement systems can be identified and measured and to an extent. reduced. Additionai data can be collected. more representative data can be collected. and more precise analytic methods can be used at any point in the environmental restoration process. However. despite the effor to reduce uncerainty through caretul design of sampling and analysis efforts. uncerainty will remain in knowiedge of site conditions. the ability of a remedial technology to periorm, and the regulatory requirements (e.g., potential changes in cleanup goals). These remaining uncertainties must be managed.

SAFER is a methodology that allows an explicir (i.e., formal and documented) optimization between reducing uncertainty in environmental restoration decisions and managing uncertainty during remediation. The objective is to identify how much effor should be put into reducing uncerainty through data collection and into managing uncerainty, to facilitate continued prudent progress toward remediation. This.balance is highly dependent on site-, technology-, and regulatory-specific conditions.

An introduction to SAFER terminology and concepts follows.

\section{SAFER Terminology}

SAFER uses terminology derived from the observational approach and the DQO process. The following list of definitions introduces many of the SAFER terms used in this module.

DOE project team (aiso, internal project team). The group responsible for conducting the RI/FS at a DOE site. As used in this guidance. the DOE project team includes DOE personnel and DOE contractors who will conduct the RI/FS and develop its reports.

Extended project team. The individuals (internal and external) who will interact throughout the RIFS project and who are responsible for directing, managing, conducting, and approving an RI/FS at a DOE facility. As used in this guidance, the extended project team is composed of the DOE project team. EPA and State reguiatory staff, and relevant public interest groups.

Stakeholder. Any person or group interested in or affected by an RI/FS project conducted at a DOE facility. 


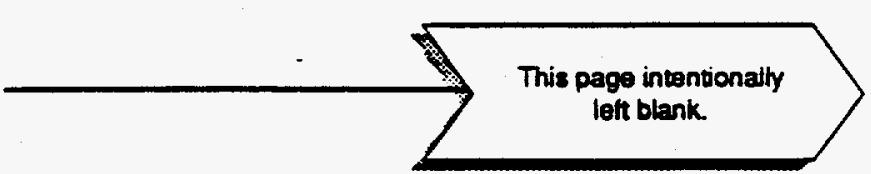

7.8

B. 8 


\section{Submodule 7.1 SAFER Introduction (continued)}

Probable Conditions. The best understanding of what the data and other information suggest as the conditions (e.g., contaminants, pathways. receptors) and constraints that a remedy must address or meet (e.g., regulatory requirements). Based on probable conditions. problems that require remediation are identified as the focus of the RI/FS project.

Uncertainty. Questions or gaps in knowledge that affect the ability to remediate the site. Uncertainty that does not impact remediation of the site is not of interest to SAFER. SAFER attributes uncertainty to the following:

- Measurement system limitations in accurately collecting, analyzing, and evaiuating environmental data

- Incomplete knowledge of site conditions

- Inability to predict remedial technology performance

- Changing or unclear regulatory requirements

Uncertainties are addressed in one of two ways: (1) the measurement system is enhanced (e.g.. additional data collection, better analytical techniques) to reduce the uncerainty to acceptable levels or (2) the uncerainty is acknowiedged and expressed as a reasonable deviation to probable conditions. A contingency plan is then developed to use in the event that the physical or chemical nature of the site does not permit impiementation of the alternative as originally envisioned (i.e.. the reasonable deviation occurs).

Measurement System. Defines what is measured. how it is measured. and how it is evaluated. In environmental restoration. measurement systems usually consist of what environmental data should be collected, how it should be collected in the field. how samples should be packaged and transported. how samples should be analyzed in the laboratory, and how data will be evaluated. Measurement systems are used during the RI. in treatability studies, and in monitoring site conditions during remediation.

Decision Rule. Establishes the relationship between the decision that is being made and the types and quality of data collected to suppor the decision. Decision rules generally are "If . . ., then ... statements that establish what decisions or actions will be taken depending upon the data evaluation. Development of decision rules forces a focus on the real need for a particular type of data and tends to reduce data collection to an essential minimum.

Decision rules are based on probable conditions. Formulation of a decision rule enables stakebolders to specify an acceptable limit to total error in the measurement system. By carefully designing measurement systems. the uncertainty that results from collection, analysis, and evaluation can be reduced but not eliminated. This streamlines the RI/FS by explicitly identifying the following with stakebolder agreement:

- The raw data to be collected and how they will be combined into a result suitable for decisionmaking 


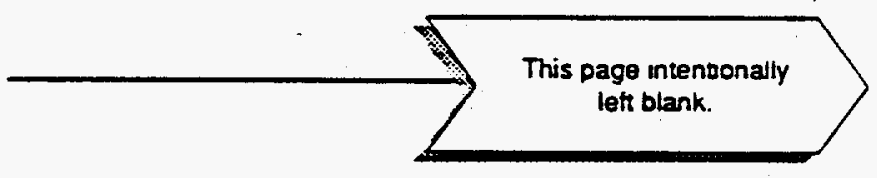

B. 10 
Submodule 7.1 SAFER Introduction (continued)

- The basis tor what the result will be compared with. or how it will be evaluated (e.g., action level. cleanup goal)

- The action that will be taken on the basis of this evaluation

Deviation. Possible alternative conditions (regulatory, technical. site) to probable conditions based on current understanding.

Reasonable deviation. A deviation irom the probable conditions that has been judged by the extended project team as sufficiently likely to be encountered such that a contingency plan should be developed.

Unreasonable deviation. A deviation from probable conditions that has been judged by the stakeholders to be unlikely, or a deviation for which a contingency plan cannot be identified. The latter type of unreasonable deviation usually results in an identified data gap that will have to be filled through data collection efforts.

Contingency plan. A plan of action pre-arranged in the event that a reasonable deviation from the probabie site conditions is encountered during remediation. A contingency plan is one of the primary means by which an uncertainty is addressed under SAFER.

Monitoring plan. During remediation, the site is monitored to detect any of the identified reasonable (potential) deviations. The monitoring plan is developed in concept during the FS and in detail during the RD phase. The monitoring plan may require modification following implementarion of a contingency plan.

\section{Organization}

Submodule 7.1 discusses the following:

- $\quad$ SAFER Assumpions

- SAFER Framework

- . SAFER Essential Elements

\section{Assumprions}

Uncerainty in environmental restoration exists at project, programmatic. operations facility, and deparment levels. SAFER was developed to focus on project-level [i.e., operable unit (OU)] issues. Additional information on tenets of the parent approaches that can be extended to uncertainty at other leveis can be found by consulting the Sources [e.g., (Wallace. 1991)].

Administrative uncerzainty (e.g.. Congressional funding, contract vehicies, and management issues) potentially impede progress in environmental restoration activities at the project level. Although these issues have regular and significant impact on environmental restoration projects, they are beyond the scope of SAFER. SAFER is designed to achieve progress toward a remedial goal, mutually agreed upon by stakeholders, while managing uncerainties in site knowledge, remedial technology performance, and regulatory requirements. SAFER does not address the following: 


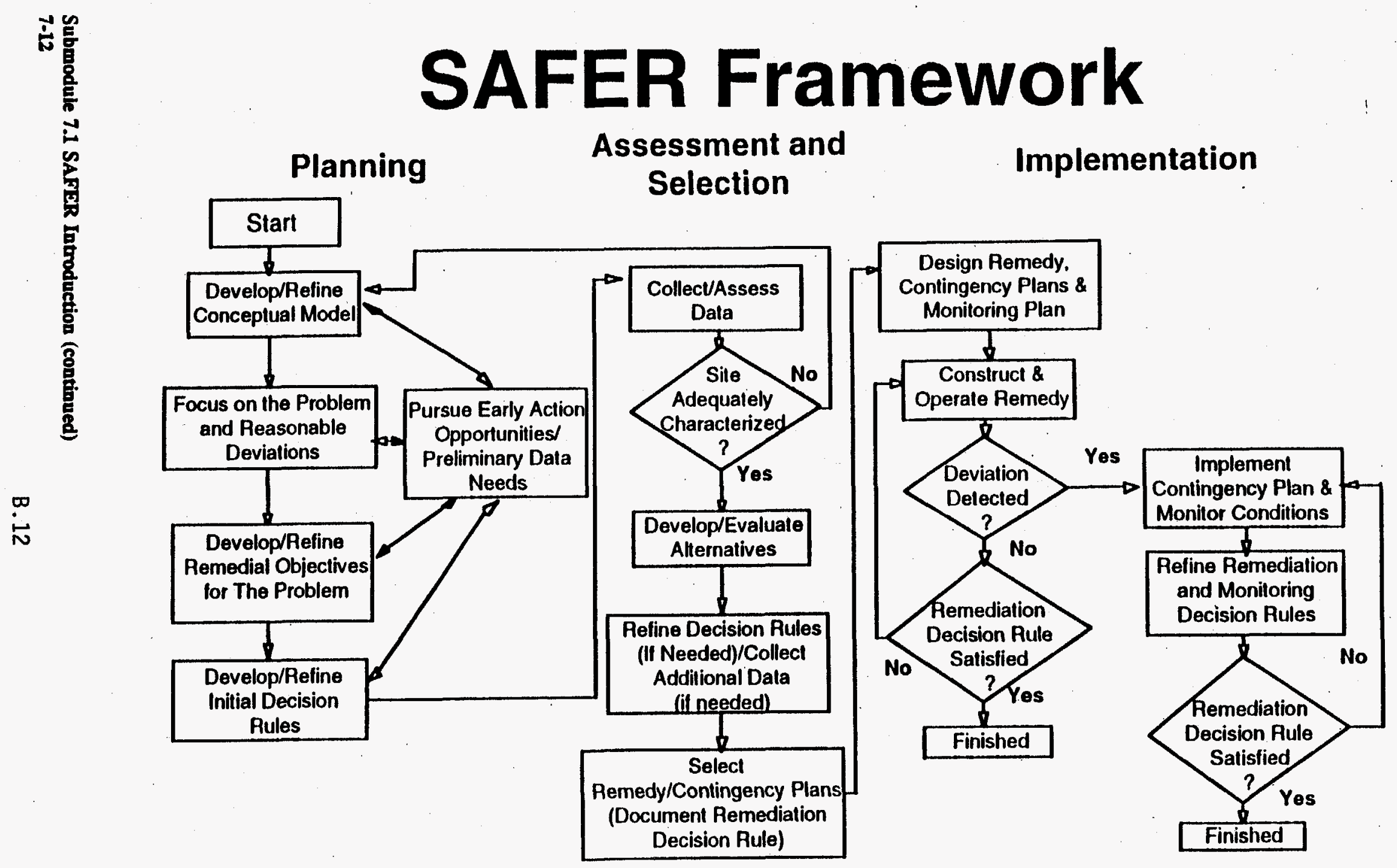

Figure 1 
Submodule 7.1 SAFER Introduction (continued)

- Determining if the waste site is a perceived problem [e.g., Hazard Ranking System (HRS) scoring and inciusion on the National Priorities List (NPL)]. The SAFER process begins at the point where available dara are evaiuated to best determine existing conditions at the waste site. The determination that the waste site requires further action (e.g., limited investigation. no-action. interim remedial action. remedial action) to address a perceived problem is assumed.

-

Determining which regulatory framework (e.g., CERCLA, RCRA) applies. SAFER is sufficiently flexible to operate under a variery of regulatory authorities [e.g., Uranium Mill Tailings Remedial Action Program (UMTRAP), CERCLA. Formeriy Litilized Sites Remedial Action Program (FUSRAP), RCRA]. SAFER assumes that the appropriate regulatory authority for the waste site has been determined.

$\bullet$

Obtaining project funds. Any environmental restoration project is dependent upon adequate and timely funding. SAFER does not address funding uncertainties; it assumes that the process of requesting and obtaining secure tunding will not be a problem.

-

Identifying stakeholders. Stakeholders play an integral role at DOE facilities. particularly in environmental restoration activities. SAFER encourages and presumes active stakeholder participation. SAFER assumes that the stakeholders and their roles in the environmental restoration process have been previously defined on a site-specific basis for a particular environmeatal restoration project.

\section{Framework}

Figure 1 shows the entire SAFER process in a CERCLA regulatory tramework. Although in this diagram SAFER appears to be a linear process. it is similar to the CERCLA process in that both are highly iterative. For example. data collection efforts during the RI are based on current site understanding and are designed to till identified data needs such as requirements for evaluaring potential remedial actions. After data collection and evaluation. the site understanding (inciuding funher data needs) changes. Similar iterarive or teedback processes exist throughout the SAFER process.

Scoping, or planning, is more strongly emphasized in the SAFER approach when compared with the way CERCLA projects have been pertormed in the past. A tocused RI/FS study is facilitated by the increased effor that is put into Scoping. For instance. SAFER encourages maxımizing the use of available data to focus the RI and to converge quickly on a range of realistic remedial alternatives. Focusing an RI/FS provides a means for acceierating the initiation of remediation.

Addressing issues such as remedial action objectives (RAOs) and potential remedial actions eariy in the process also allows a focused RI/FS. Aggressive remedy assessment and selection is possible with SAFER because these processes are conducted on the basis of the probable conditions at a waste site. Possible deviations to probable conditions are identified and addressed if they inhibit the ability to identify the appropriate remedy or potentially inhibit implementation and operation of the remedy. Uncertainties. which can lead to deviations, are addressed in two ways - by elimination through data collection or by management through development of contingency plans. Decision rules are formulated to cleariy identify data needs and data uses. When very explicit data needs are derived from the decision rules, the data collection efforts are strongly focused and reduced to the essential minimum. Contingency plans are developed for use during remediation to manage certainties and associated potential deviations that are not eliminated through data collection. 


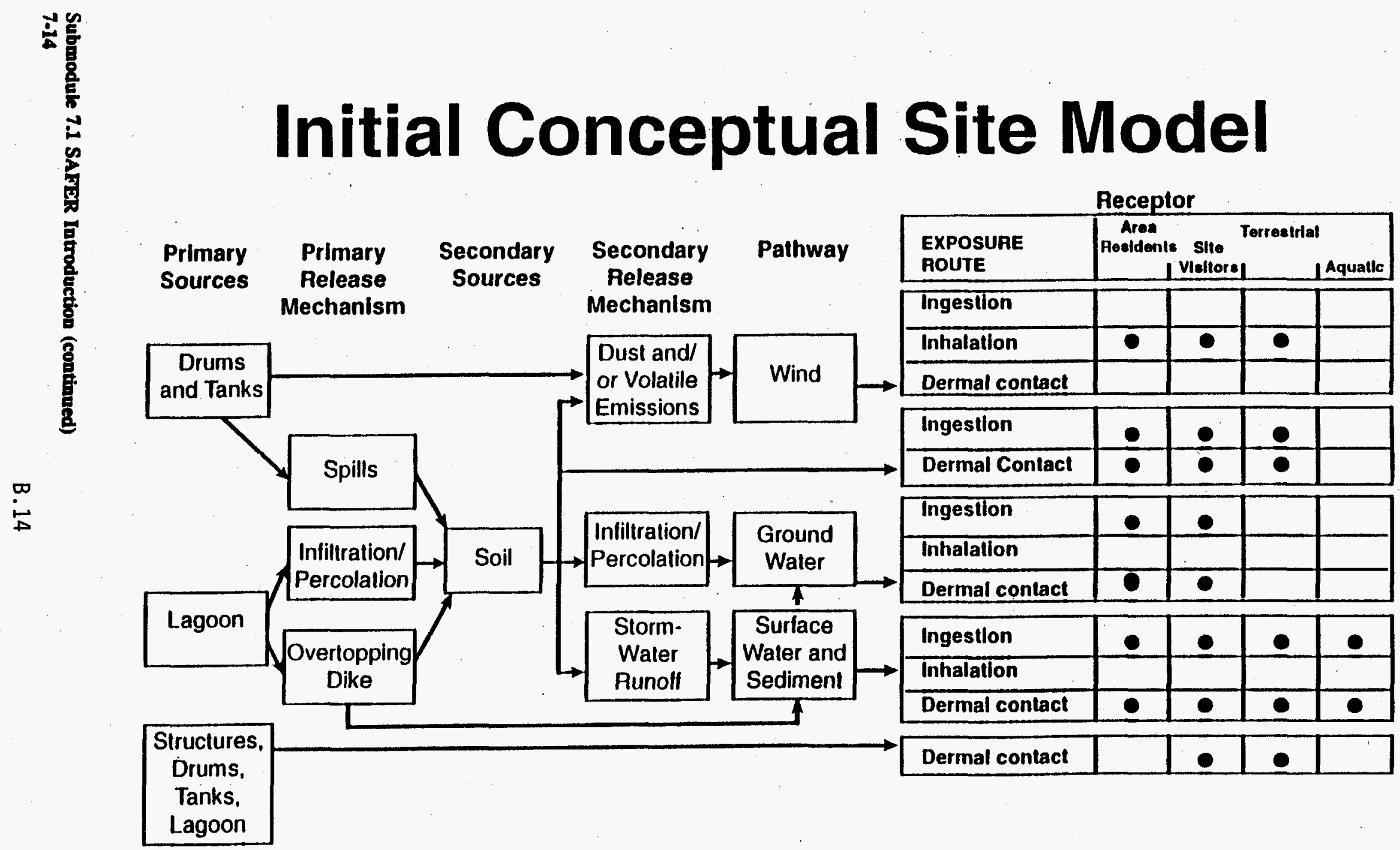

Figure 2 
During detailed design of the remedial action. contingency pians and monitoring plans are also designed in more detail. During implementation. monitoring systems identify the need to implement a specific contingency plan. The contingency plan provides the necessary modification of the remedial action to help ensure that progress toward the remedial goal continues with minimal delay. Decision rules are used to identify data that are collected during monitoring to identify deviations and to determine when the remedial goals have been accomplished.

\section{Essential Elements}

SAFER has four essential elements: (1) defining and using a conceprual model to provide a foundation for remedial planning and action: (2) planning and conducting assessment. remedy selection. and remedial action on a "Learn-as-you-go" basis: (3) recognizing the management of uncertainty as a key to conducting each phase of the remedial process; and (4) recognizing the role and contributions of stakeholders. If these elements are not formally part of the environmental restoration activity (i.e.. documented in compliance reports), then SAFER is not being applied.

The application of each element is dynamic during the environmental restoration process. For example. based on the initial understanding of regulatory requirements and site conditions. site unceriainty might appear to be readily manageable during remediation. However. following a limited field investigation (LFI), the implications of the uncertainty may resuit in the need for additional investigation to reduce uncertainty to manageable levels. The other elements aiso will be dynamic throughout the SAFER process.

Element 1-Conceptual model as a foundation for the environmental restoration process. A summary representation (pictorial, written. or both) of key site conditions. inciuding likely contaminant sources (and their physical and chemical characteristics), contaminated media. pathways, and receptors. Figure 2 shows a simplified example of one type of conceptual model. (Submodule 1.2. Note C. provides a detailed example of a conceptual model.)

The conceptual model is initially based on existing site information. key assumptions. and extended project team perspectives. and evolves as remedial planning and action proceed. SAFER uses the conceprual model as a primary tool to streamiline planning and remediation. SAFER focuses on ideatifying relevant uncertainty key to remediation and on testing and veritying the uncertainty and assumptions in the conceptual model. Thus, the conceptual model facilitates focus on problem(s) and their potential solutions and highlights principal uncerrainty.

The conceptual site model is a dynamic picrure of current site understanding. It requires periodic refinement as new information is gained throughout the remedial process. Revisions are necessary as assumptions based on available data are confirmed. made uncertain, or proven false by the introduction of new information.

As a tool. the concepual site model provides identification and representation of uncerainties in the areas of concern to remediation (e.g., waste sources, pathways, release mechanisms). The conceptual model helps make data gaps apparent. Data gaps result from uncerainties in characterization information (e.g., demographics for risk. fate. and transport data: physical soil properties: contaminants of concern). A data gap is any insufficiency in information to support the baseline risk assessment. identification of applicable or relevant and appropriate requirements (ARARs), and development and evaluation of remedial aiternatives. 


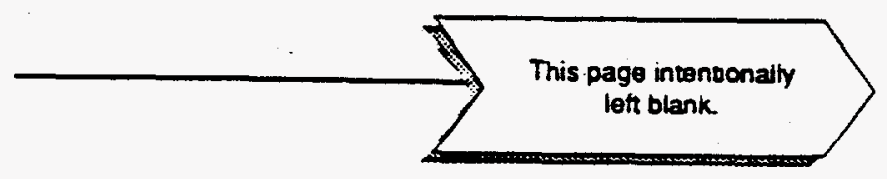

7.16

B. 16 
Element 2-Plans and designs based on learn-as-you-go. The remedial process is inherently dynamicuncertainty will continue to exist throughout the remedial process. and will change as remediation proceeds.

Each step of the SAFER process builds. in specific ways, on the outpur of earlier steps (see Figure 1). Learning is constantly occurring throughout the remedial process. therefore by necessity, SAFER allows tor new knowiedge to be incorporated throughout the process. This will result in retining eariier decisions. Designed to be an iterative process. SAFER makes extensive use of feedback loops in the management of uncertainty.

Three examples of feedback loops in SAFER: (1) During planning, the formulation of a decision rule may indicate that a different problem is of interest. (2) During assessment. alternatives evaluation may indicate that a deviation thought to be reasonable and manageable cannot be handled by developing a contingency plan. This results in the consideration of additional potential remedial alternatives or the identification of new data needs. (3) During remediation. acrual pertormance of the remedy (as indicated by monitoring) may require revised remediation goals or remediation decision rules.

Through learn-as-you-go. SAFER emphasizes optimizing the management of uncertainty, intervening at the best points (as identified by the extended project team) in the process to manage uncertainty with the appropriate techniques (as identified by the extended project team) to ensure the proper balance between planning and action.

Element 3-Recognition of explicit uncertainty and development of management techniques. At any point during the RI/FS/RD/RA process. data deficits and knowledge deficits exist that affect the ability to remediate the site. Uncertainty that does not impact remediation of the site is not of interest to SAFER. The fundamental sources of uncertainty are as follows:

- Incomplete knowledge of site conditions. Best knowledge of site conditions is summarized in the conceptual model.

- Inability to predict remedial technology pertormance. While the performance of some remedial technologies may be weil understood in controlled environments. such as laboratory tests. uncerainties about site conditions render prediction of remedial technology periormance in the field as more uncerain. Other especially innovative technologies may not be as weil understood. which results in considerable additional uncertainty about technology performance.

- Changing or unclear regulatory requirements. The regulatory environment that DOE environmental restoration activities operate within is dynamic. Final interpretations or determinations of regulatory issues and constraints (e.g., assumed future land use. cieanup criteria) contribute to uncerainty about remedial goals.

Note that each of these areas is dependent upon data to determine probable conditions or probable performance. A measurement system must be defined to provide and evaluate the needed data. Measurement systems are also sources of uncertainty. By carefully designing measurement systems. uncertainty that is inherent in collection. analysis. and evaluation can be reduced and managed, but not entirely eliminated.

For environmental restoration to progress, the only choice is to operate under conditions of uncertainty. Stakeholders must be able to define (1) the overall level (cumulative of all sources) of uncerainty that is 


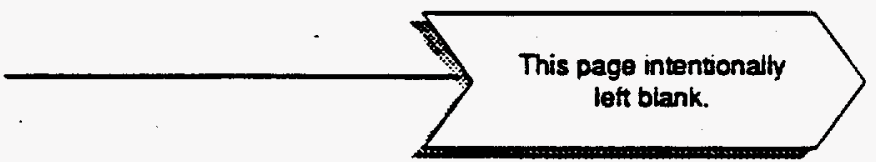

$7-18$

B. 18 
Submodule 7.1 SAFER Introduction (continued)

acceptable at each point in the process and (2) the techniques for managing the uncertainty that will be applied at each point in the process. In general. the two approaches for dealing with uncenainty are (1) reducing it by careful design of a measurement system (typically data collection) and (2) managing it by developing contingency plans.

Optimization of uncerainty management is different at each site. It may be sensibie to collect a "great amount" of data during planning to reduce uncerainty (see Submodule 8.1) or it may be likewise sensible to rely on a remedy that allows uncerzainty to be readily managed during remediation (see Submodule 8.2).

Element 4-Stakehoiders. Traditionally. the extended project team and other stakeholders play an instrumental role in identifying applicable regulatory frameworks, establishing budgets and schedules, and determuning information requirements. In the SAFER framework. stakeholders continue to perform these functions, but they also make additional contributions that are crucial to the effective management of uncertainty. These contributions include the following:

- Participation in developing the overall site-specific strategy for dealing with uncerainty

- Input to and understanding and acceptance of the conceptual model

- Consensus on actual șite problems to be addressed

- Determination of furure land use and other issues pertinent to the establishment of RAOs

- For each data collection effor. description of the qualitative consequences of error. which are translated into quantitative data performance criteria by the extended project team

- Agreement on reasonable deviations and associated contingency plans

- Acceptance of a decision document that includes all of the output described above

- Active monitoring and involvement about uncerainty issues as remedial action proceeds

Submodule 7.1 SAFER Introduction (continued) 


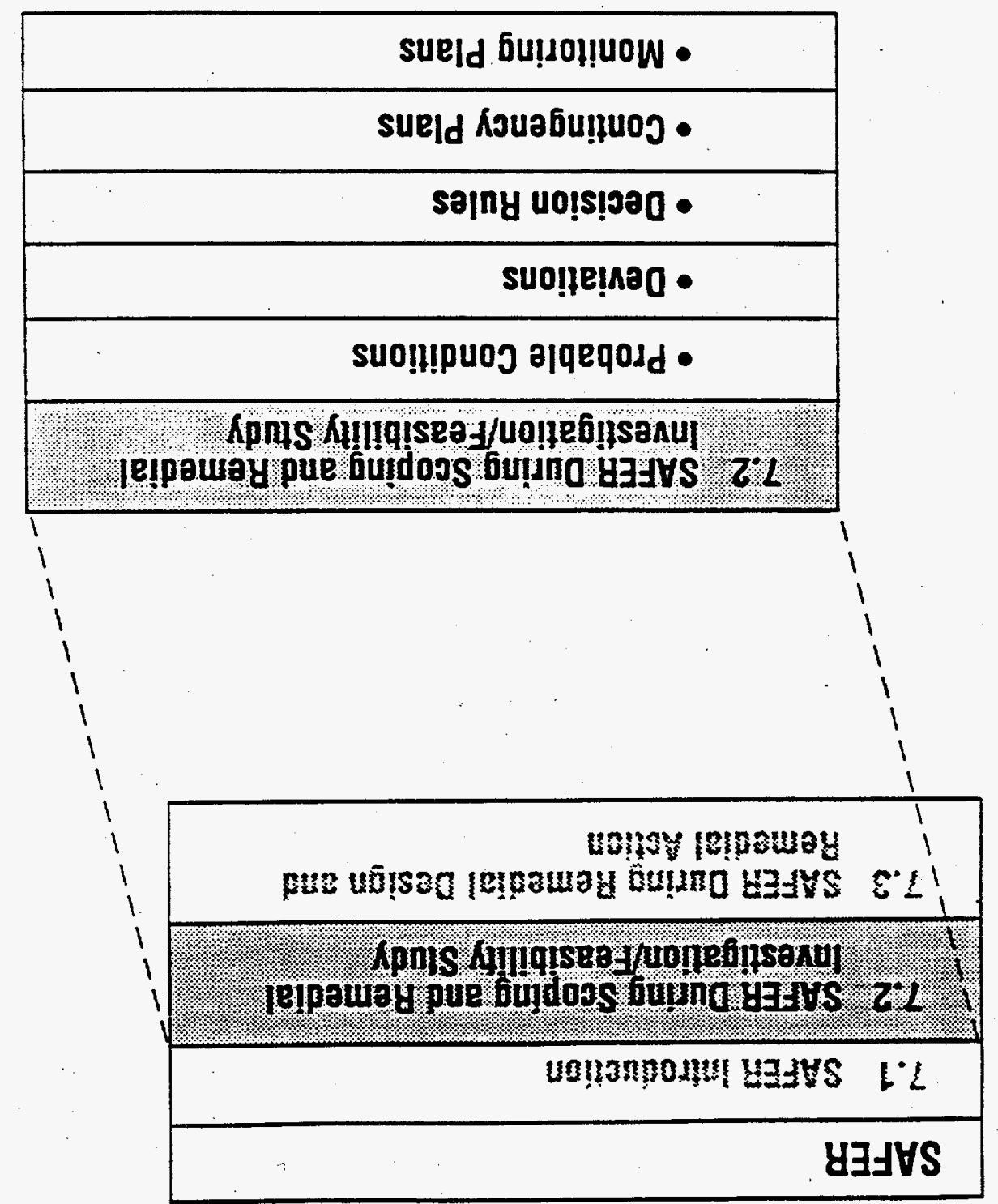

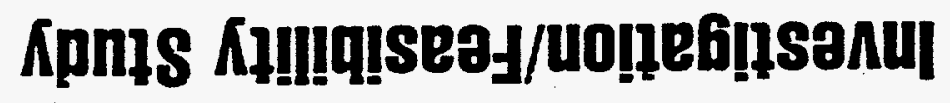

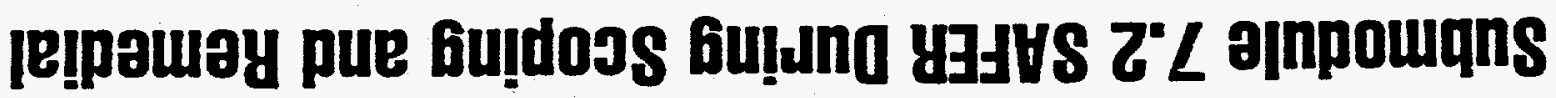




\section{Background}

The environmental restoration process consists of two broad phases that. to be etfective and efficient. must be considered as a continuum: defining the risk to human health and the environment posed by the site. determining the appropriare remedy to the perceived problem. and implementing that remedy. In CERCLA. the process of characterizing the site. defining the risk. and determining the remedy includes Scoping, RI/FS, and remedy selection. SAFER uses the concepts of probable conditions. deviations. decision rules, and contingency plans to achieve enhanced planning. focused investigations. and aggressive alternative assessment and remedy selection. SAFER streamlines the CERCLA process by providing a framework to optimize the management of uncerainty through the use of a conceptual model. incorporating new information as it is learned. and integrating the extended project team in the decisions about characterization and remediation.

This module highlights the role of SAFER concepts in streamlining the Scoping/RI/FS process.

\section{Organization}

Submodule 7.2 discusses the following:
- Probable Conditions
- Deviations
- Decision Rules
- Contingency Plans
- Monitoring Plans

In addition, more detailed information is provided in the following notes:

- $\quad$ Note A-Discomiont Curves

- Note B-Deviations and Contungency Plan Development 


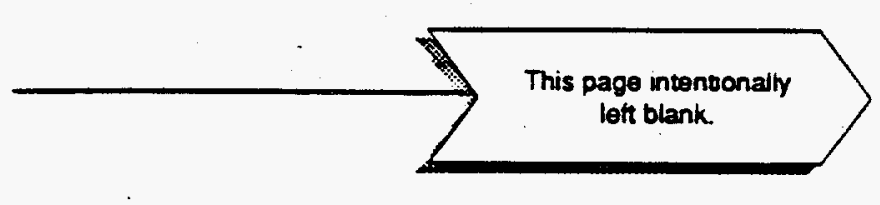

7.22

B. 22 
Submodule 7.2 SAFER During Scoping and Remedial Investigation/Feasibility Study (continued)

\section{Probable Conditions}

The probable conditions of the site establish the focus tor the project: they are the basis for Scoping and the RI/FS. This acts to streamline Scoping/RI/FS by providing the basis for decisionmaking by the extended project team in areas such as prioritizing problems the remedy must address, alternatives evaluation. ARARs determination. risk assessment, and remedy selection.

Scoping. During scoping, probable conditions are based on available data. the working hypothesis. and assumptions and conjecture about the waste site. The probabie conditions should be defined as completely as possible. short of mere guessing, during Scoping. Uncerainties about probable conditions are noted. Preliminary evaluarions, such as preliminary ARARs identification. are based on the initial probable conditions. Data needs are the result of the inability to make decisions (e.g., what are the RAOs?) based on the existing understanding of probable conditions. This results in focusing data collection activities on confirming probable conditions.

Summary information of the site's probable conditions and uncertainties form the conceptual model. Probable conditions will be revised on the basis of new information gained during the RI/FS. Similarly, the conceprual model will be revised. The conceptual model is the best overall picture of the probable conditions. The extended project team will exercise judgment to define what is probable, unlikely, and uncerain.

Remedial Investigation. One of the primary purposes of the RI is to further develop, refine, and confirm the problems to be addressed by collecting specific data required to make decisions about waste-site restoration. After the RI is complete. the probable conditions should be known to the extent necessary to meet specified expectations of the extended project team. For example. "Are the probable conditions defined sutficiently to support decisions that will be made on the basis of the baseline risk assessment?"

The conceptual model is updated on the basis of new understanding of probable conditions.

Feasibility Study. The probable conditions are the basis for (1) development, screening. definition. and evaiuation of remedial alternatives: (2) the baseine risk assessment: and (3) the ARARs evaiuation. These three evaiuations are conducted under the assumption that the probable conditions are the acrual conditions met in the field.

The extended project team again provides the judgment on the adequacy of probable conditions to support these evaluations. Note that "adequacy" in SAFER is defined by the extended project team.

The evaluations may be iterative to the extent that probable conditions are based on new information from the RI. Basing these evaluations on probable conditions allows for rapid convergence on likely remedial alternatives. relative to waiting for "complete characterization."

\section{Deviations}

Deviations to probable conditions represent uncertainty (e.g., site conditions, technology performance, regulatory requirements) that must be addressed during the RD/RA. The uncertainty represented by deviations is the uncerainty that could not be reduced through data collection, or did not need to be reduced because it could be managed during the RD/RA.

Submodule 7.2 SAFER During Scoping and Remedial Investigation/Feasibility Study (continued) 


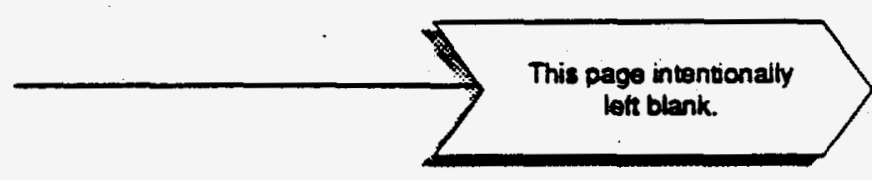

B. 24 
Identifying which deviations are reasonable and preparing contingency plans to address them is a primary SAFER technique. This process of identifying reasonable deviations streamlines the RI/FS by eliminating the need to exhaustively attempt to eliminate uncerainty.

Scoping. Possible deviations to probable conditions are first identified as uncerainties in the probable conditions. At this point. deviations will represent a wide range of altemative conditions because of the uncerrainty of site conditions. Deviations to probable conditions are easily identrited as a result of uncertainties portrayed in the conceptual model.

Deviations do not represent data needs - data collection is focused on contirming probable conditions and remedial problems. not on contirming deviations. Deviations are found to exist when probable conditions are not contimed: These then become revised probable conditions. During Scoping, data needs are based upon the necessity to reduce uncertainty with decisions based on probable conditions.

Remedial Investigation. The ensemble of possible deviations is revised based on the revised understanding of probable conditions. As probable conditions are confirmed the possible deviations are reduced in number and magnitude. This process results in identifying reasonable deviations to the probable conditions based on site understanding. The extended project team defines what constitutes a reasonable deviation based on understanding of site conditions. Unreasonable deviations to probable site conditions are discarded. The process of identifying reasonable deviations streamlines the RI/FS by focusing on uncertainty that realistically could impact the process of restoring the site.

The conceptual model. revised on the basis of new information. provides the extended project team and other stakeholders with the ability to distinguish between reasonable and unreasonabie deviations based on site understanding.

Feasibility Study. The ensemble of reasonable deviations are further defined during the FS by considering as "reasonable" only those deviations that will impact the remedial alternatives under consideration. Unreasonable deviations in this instance are deviations that may be possible based on site understanding, but do not impact the remedial alternatives. These technology-based unreasonable deviations also are discarded. Note that technology-based unreasonable deviations are a function of the technologies being considered as par of the remedial alternative. For example. although the concentration of lead in the soil may not impact ex-situ stabilization. it does impact incineration.

Unreasonable deviations also result from the inability to identify specific contingency plans to manage the deviation. This type of unreasonable deviation resuits in the necessity to further define probable conditions. or to identify shoricomings of the remedial alternatives. If methods to manage the reasonable deviations cannot be identified (i.e.. contingency plans). specific data needs may result.

This process of continuousiy refining reasonable deviations based on new information acts to streamine the RI/FS by focusing only on uncerrainties that must be managed, discarding uncerainties that are irrelevant to waste-site restoration.

During the FS, the extended project team continues to define "reasonableness." and the conceprual model continues to provide a ready tool to assess "reasonableness."

Submodule 7.2 SAFER During Scoping and Remedial Investigation/Feasibility Study (continued) 


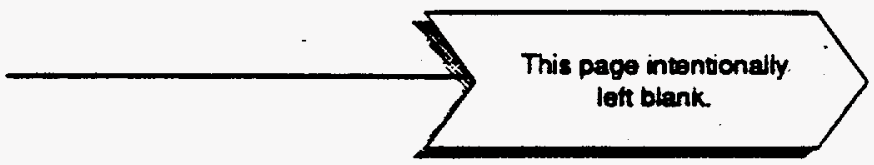

7.26

B. 26 
Submodule 7.2 SAFER During Scoping and Remedial Investigation/Feasibility Study (continued)

\section{Decision Rules}

Decision rules, based on problems that probable conditions indicate as existing, summarize how uncerainty will be reduced by the data measurement system. Decision rules proactiveiy and explicitly tie decisionmaking to data needs and uses. This streamines the data collection process by ensuring that analytic and field techniques are commensurate with the data use (i.e.. decision) and ensuring that these data are being used to suppor a specific decision or set of decisions. Note that this does not necessarily imply less sampling - rather it implies identifying optimal data measurement techniques for decisions that must be made as part of the RI/FS. Data collection to reduce uncertainty must aiways be balanced against the ability to manage uncertainty (via the contingency pian) during the RD/RA.

Decision rules also act to streamline because the extended project team explicitly defines what data measurement systems are adequate for decisionmaking. A previously defined "stopping rule" minimizes the opportunity for extended project team miscommunication about when to stop sampling.

Scoping. During Scoping. decision rules generally deal with characterization issues at a minimum. These decision rules will establish the focus of the investigation. For example. the decision for the volume of contaminared soil to address will be formulated into a decision rule by identifying the type of data to be collected, the quality and quantity of samples. the measurement technique, the basis for the decision. and the action resulting from the decision (e.g., this volume will be remediated). Characterization issues may be resolved with "one-pass". data collection as another means of streaminining.

Opportunities for early action (e.g., removal actions. interim remedial actions) are always available as another means of streamlining. When opportunities tor early actions arise. decision rules may begin dealing with remediation decisions (e.g., what soil to remove, when to stop digging). In a full-scale RI/FS, these issues will typically be dealt with during the FS.

The extended project team will specify the level of uncertainty they require in making the characterization decision. This may be a phased decision - first determining if action is required (i.e.. characterization sufficient to suppor baseline risk), with following decisions tocused on sufficient characterization to suppor development and evaluation of alternatives and ARARs analysis. Transiating stakeholder "comion" with making decisions to uncertainty constraints on data measurement systems is difficult. Submodule 7.2. Note A. provides additional detail on one SAFER technique-discomforr curves.

Decision rules that are used in the work plan will help to define the Sampling and Analysis Plan (SAP) and the Quality Assurance Project Plan (QAPP).

Remedial Investigation. The data measurement system necessary to support sufficient site characterization has been pre-established by the extended project team by formulation of decision rules during Scoping. Characterization decision rules and associated data needs are revised on the basis of new information.

Feasibility Study. Decisions begin to focus on remediation issues, such as the necessity for further action. when the site is restored, and how determining when a deviation is occurring. 


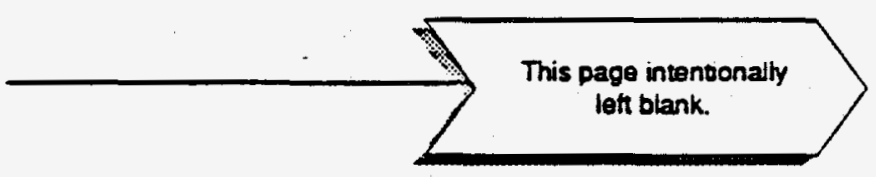

7.28

B. 28 
Submodule 7.2 SAFER During Scoping and Remedial Investigation/Feasibility Study (continued)

Decision rules for remediation goals are directly related to the choice of remedial alternative because of the individuality of technologies (e.g., in situ stabilization has different remediation results than does ex situ treatment). Remediation decision rules will be finalized in the Record of Decision (ROD) when the selection of the remedial alternative is finalized.

Decision rules for identifying deviations during remediation are based on how to distinguish deviations from probable conditions. These also will be directly related to the type of technologies that are a part of remedial altematives. During the FS these monitoring decision rules are only conceprually defined. They are detined in detail during the RD/RA.

\section{Contingency Plans}

Contingency plans are par of managing uncerrainty during the RD/RA. Contingency plans are technologyspecific and based on the definition of reasonable deviations. The ability to manage uncenainty during the RD/RA streamlines the RI/FS by reducing the need to continually retine probable conditions by collecting data until minimal uncerainty exists. The net result is to ensure that the data collection that does occur is minimized by balancing the need to reduce uncerainty with the ability to manage it.

Contingency plans play only a conceptual role during the RI/FS. They are defined in detail during the RD/RA.

Scoping. Contingency plans are technology-specific. Contingency plans do not play a large role until technologies can be adequarely defined. Their existence may be evaluated as a par of determining whether uncertainties in probable conditions can be managed. (See Submodule 7.2, Note B.)

Remedial Investigation. Contingency plans have a minimal role in the RI.

Feasibility Study. The need to actually implement a contingency pian is identified by evaluating the impact of reasonable deviations on likely remedial alternatives during the FS. During the FS. contingency pians have to be sufficiently developed to allow evaluation of the remedial altenative. Contingency plans are defined in detail during the RD/RA. The accompanying graphic provides some example contingency plans during RI/FS. (Also see Submodule 5.1. Note B.)

During the FS, two options exist if a contingency plan cannot be identified for a deviation: (1) additional data can be collected to further reduce the uncerrainty in the probable conditions and technology pertormance. therefore better defining or eliminating the reasonable deviation. (2) The alternative (technology) becomes an unlikely remedial alternative based on evaluation criteria. The FS is thus streamilined by helping to focus on remedial alternarives that can address probable conditions and reasonable deviations. This eliminates alternatives that cannot adequately manage existing uncerainty, or identifies the need to further reduce the uncertainty before the alternative can be effective.

Submodule 7.2. Note B, provides a template for assessing deviations and the need for contingency plans.

Submodule 7.2 SAFER During Scoping and Remedial Investigation/Feasibility Study (continued) 


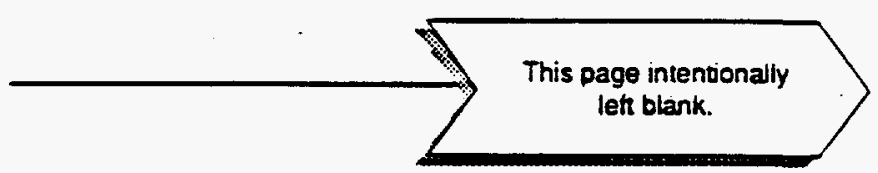

7.30

B. 30 
Submodule 7.2 SAFER During Scoping and Remedial Investigation/Feasibility Study (continued)

\section{Monitoring Plans}

Monitoring plans are pan of the ability to manage uncertainty during the RD/RA by detecting deviations. Two parts of monitoring are important: (1) identifying the deviation that is occurring and (2) identifying which contingency pian is necessary to modify the remedy.

Like contingency plans. monitoring plans are to a great extent. technology-specific. Although defined conceprually during the RI/FS. they do not play a large role in streamining until the RD/RA.

Scoping. Monitoring plans do not play a role.

Remedial Investigation. Monitoring plans do not play a role.

Feasibility Study. Monitoring plans are sufficiently detined in concept to ensure that deviations can be monitored for and detected. and to ensure that the appropriate contingency plan is identified. Submodule 7.2. Note B. provides additional detail. 


\section{Discomfort Curve}

$\underset{N}{\omega}$

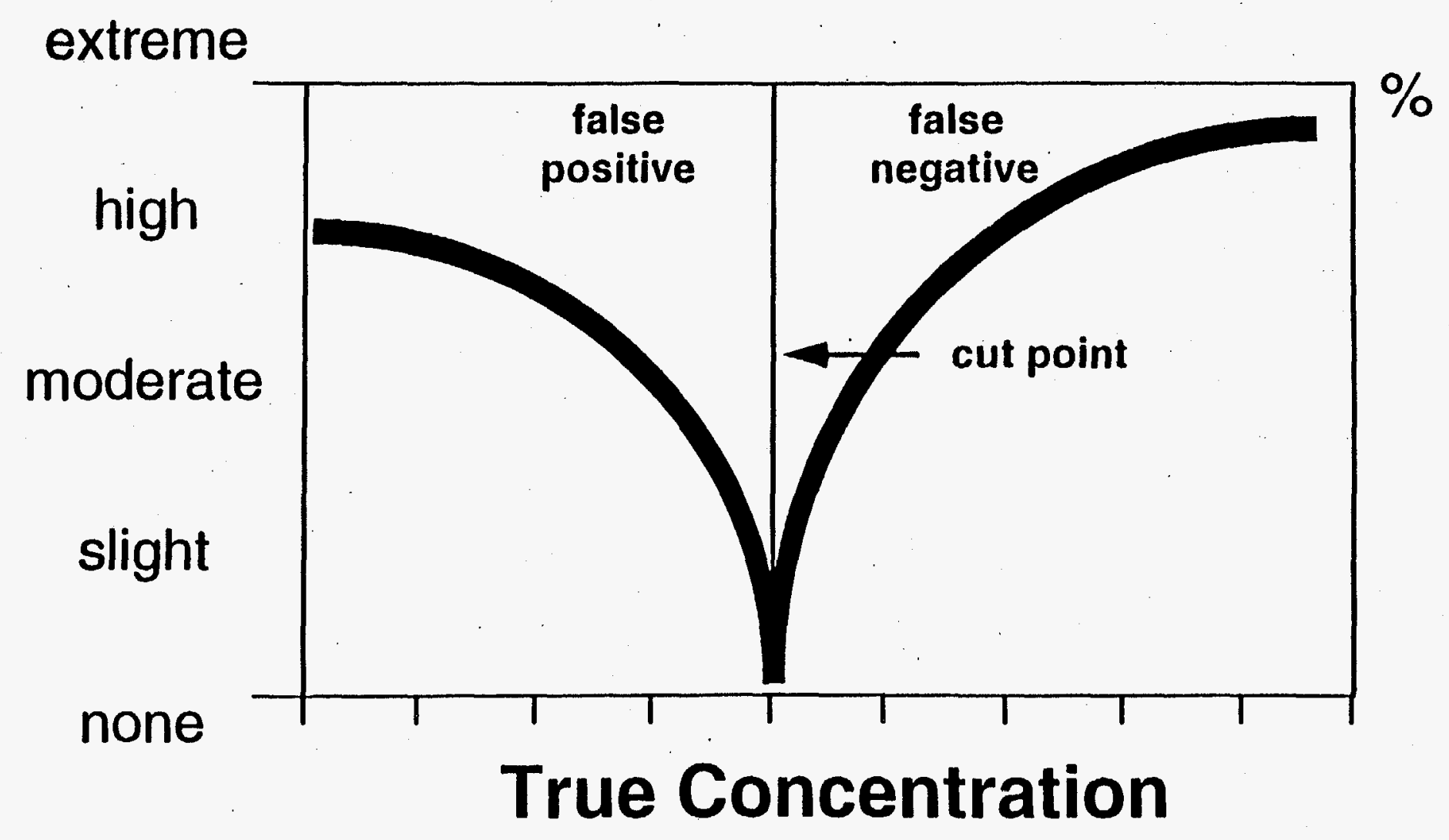


Note A. Discomfort Curves. Decision rules specify allowable error in the measurement system by incorporating a statement of uncertainty constraints. In SAFER. uncertainty constraints are quantitative statements of willingness to accept ertor in decisions based on environmental data. Decision uncerainty constraints can be directly transiated into data (measurement system) periormance criteria. Decision rules are developed to accommodate error that is acceptable in making a decision based on environmental data (e.g., the error that is acceptable in identifying a volume of soil as contaminated). One way to discuss this type of error (i.e., the chance of being wrong) is in terms of staristical Type I (false positive) and Type Il ifalse negative) error statements. A false positive in the above example is deciding that the soil is contaminated and that action is necessary when. in fact. the soil is clean. Measurement system error is the only contribution to overall uncerainty that is quantifiable and that can be explicitly limited. (Note that inherent temporal and spatial variability of environmental data is a source of uncertainty that can be estimated but not limited.)

Decision error tolerances depend on the specific narure of the decision (i.e.. they depend on how the decision rule has been formulated). The type and quality of data needed to make the decision would vary accordingly. The acceptable error is directly dependent on the consequences of the decision. and is determined in SAFER by the willingness of the extended project team to tolerate error. Further. toleration about false positives and false negatives probably is not equivalent-depending on the specific decision and the specific implications of error. For environmental restoration. a talse positive can mean taking some action and spending resources unnecessarily: a false negative can mean exposing some portion of the environment to a continuing threat.

The proper tradeoff is never obvious - it depends on the specific site. the specific decision. and the perspectives and priorities of the extended project team. SAFER manages uncertainty at this point by providing a structure through which these perspectives can be introduced. evaluated. and developed into a consensus. Once extended project team consensus is reached about a decision s qualitative ertor tolerances. it is a straightforward statistical process for the extended project ream to translate them into the required quantitative terms of the measurement system. A variety of techniques exists for discussing error quantitatively (e.g., confidence intervals and power curves). The "discomfort curve: is a tool that has proven to be very effective as a quantification of false positive and false negative error tolerances.

The benefit of quantifying decision error is that this discomfor curve (or one of the other quantitative means for depicting decision error tolerances) provides exactly what is needed to design an optimal data collection program. In other words, a rational basis now exists for allocating measurement system error. 


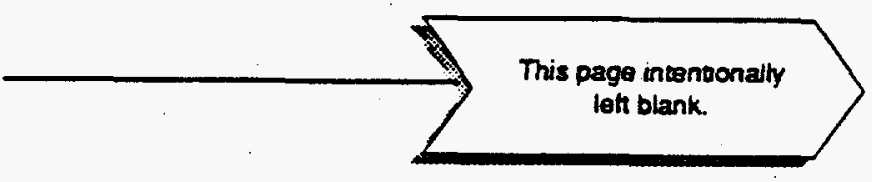

$7-34$

B. 34 
Submodule 7.2 Notes on SAFER During Scoping and Remedial Investigation/Feasibility Study (continued)

The accompanying figure shows a hypothetical discomion curve. Note that the horizontal axis is labeled "true concentration" - the point (or range) that the measurement system is trying to determine. The vertical line in the middle of the diagram represents a "cut point" - the level to distinguish (e.g., the remedial goal or an action level concentration). The determination of what constimus a cut point is dependent on the decision being made.

Note that the area to the left of this line represents a true negative. However. some portion of this area will depict talse positives - the data evaluation indicates that the cut point has been exceeded when. in fact. the cut point has not been exceeded. The right side of the line represents positives. some of which will be false negatives - the data evaluation indicates that the cut point has not been exceeded when, in fact. the cut point has been exceeded.

The left vertical axis represents the extended project team's level of concern about making a wrong decision (e.g., the qualitative error tolerances): On the right vertical axis, these qualitarive terms can be transiated into quantitative ones: the values chosen will be site-specific.

The hear of the discomfor curve is the set of curves that depicts the stakeholder's willingness of the extended project team to tolerate error in the decision being made. Generaily, the closer the true concentration is to the cut point. the lower the level of concem about error. Likewise. the further the error is from the cut point. the higher the level of concern. The same logic applies to false positives.

The shape of these curves. combined with the numerical values assigned on the right vertical axis, will determine the quantitarive decision error tolerances. The implications of false positive and false negative errors are not identical: it would. thereiore, be unlikely for these curves to have the same shape.

The discomton curve is valuable because it provides specification of total allowable error. The extended project team can now propose possible data measurement systems and demonstrate whether they meet the decision error tolerances displayed by the discomion curve (e.g., the periormance of the survey design is lower than the discomfort curve at every point). The decisionmaker can then select the optimal data measurement system on the basis of cost and performance.

Conversely, the extended project team may assess that no plausible design can meet the decision rule and associated error tolerances within current budgetary constraints (i.e., the data measurement system performance curve is higher than the discomfort curve at key points). In this instance, the options are (1) to increase the budget for data collection or (2) to relax the discomfor curve. In either event, planners can point to a logical basis for their next actions. 
Submodule 72 Notes on SAFER During Scoping and RUFS (continued)

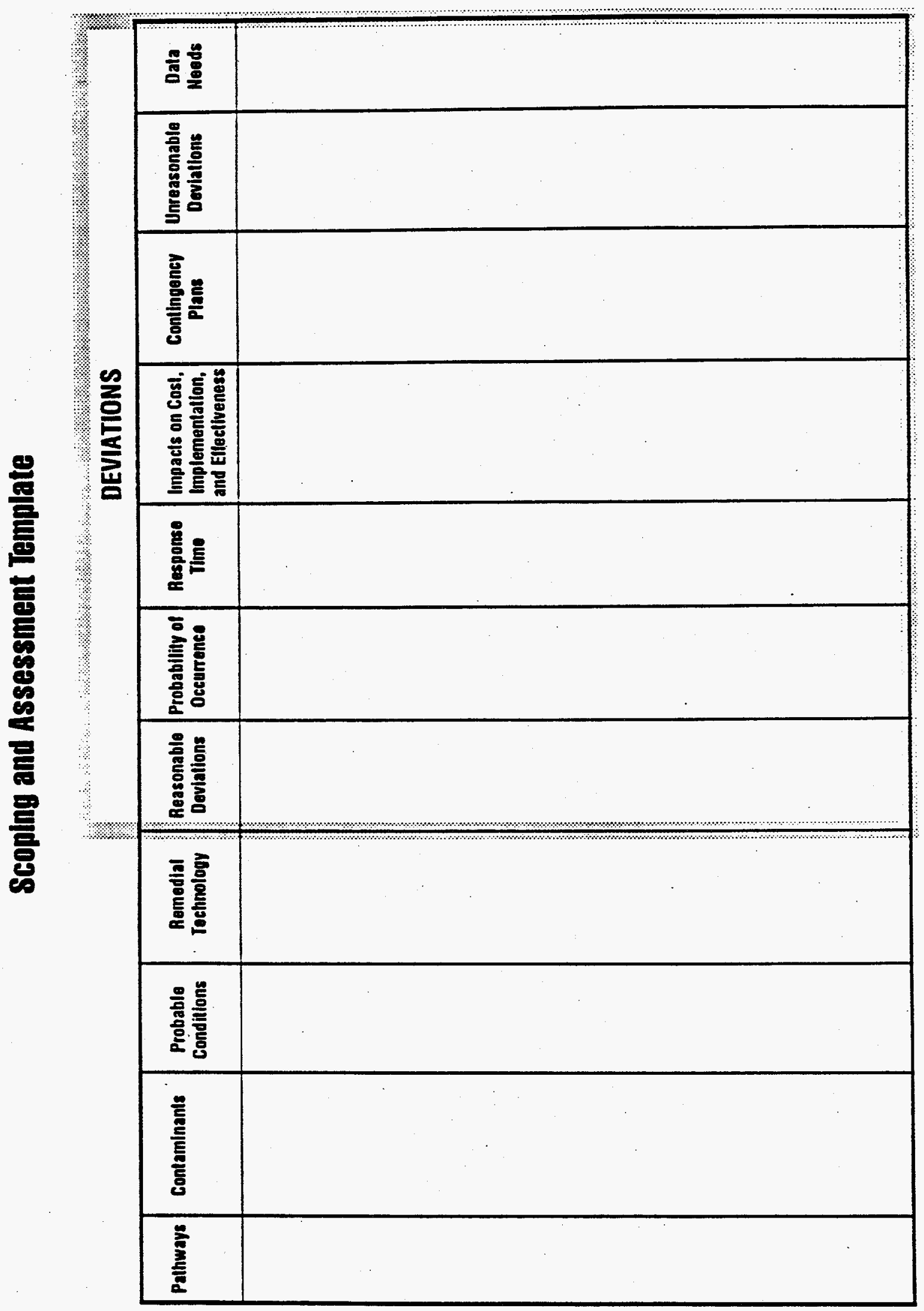

Note B: Deviations and Contingency Plan Development

7.36 
Submodule 7.2 Notes on SAFER During Scoping and Remedial Investigation/Feasibility Study (continued)

Note B. Deviations and Contingency Plan Development. The teraplate shown in the accompanying graphic can be used to summarize linked pieces of information involved in the evaluation of deviations and contingency plans. It can easiiy be created on a computer and revised and updated through the remediation process as new information becomes available. The information in the tirst three columns is summarized in the conceptual model.

The remainder of the template focuses on the potential deviations. to assist in developing and examining the effects of the remedial altematives. The elements in the deviations section of the template are as follows:

- Probability of occurrence. At this stage (and perhaps throughout the remediation process), this assessment of the deviation is probably qualitative (e.g.. high. medium. low). The objective is to identify which deviations are more likely.

- Response time. This is the likely time (qualitative or quantitative) between the detection of a deviation and the implementation of a contingency plan. If oniy a shor response time is expecred. the required level of design will be more detailed because little time will be available for the design if a deviation is detected. Thus. this element provides information on the level of detail required for the contingency plan.

- Impacts on cost. implementation. and effectiveness. These are the principal screening criteria for remedial technologies and alternatives. The evaluation of these criteria may indicate substantial impacts leading to the identification of the potential for unreasonable deviations.

- Contingency plans. Entries in this column specify the contingency plans for responding to all deviations.

- Unreasonable deviations. On the basis of the anaiysis in the columns to the left. unreasonable deviations may exist and must be addressed with additional data collection.

- Data needs. The analysis prompted by the completions of the template will help identify additional data needs for which decision rules will be formulated.

This type of table can be used to effectively communicate to the extended project team and other stakeholders the strategy of managing reasonable deviations. The extended project team will deveiop this table. 


\section{Submodule 7.3 SAFER During Remedial Design and Remedial Action}

\section{SAFER}

\subsection{SAFE Mtrodustion}

7.2 SAFER During Sroping and Pameria Investigation/Feasibility Sfuty

7.3. SAFER Buring Remedial Designand

1. Remedial Action

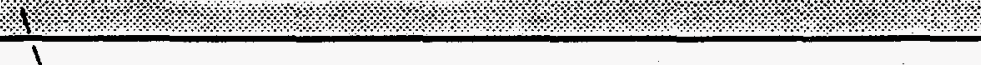
i

\begin{tabular}{|l|}
\hline \\
\hline SafER Daring Remedial Design and \\
\hline Remedial Action \\
\hline$\bullet$ Probable Conditions \\
\hline$\bullet$ Deciations \\
\hline$\bullet$ Contingency Plans \\
\hline$\bullet$ Monitoring Plans \\
\hline
\end{tabular}

7.3 SAFER During Remedial Design and Remedial Action 7.38 


\section{Background}

Remedy implementation is the second phase of the environmental restoration process. In CERCLA, the process of impiementing the remedy includes RD and RA. SAFER uses the concepts of probable conditions, deviations. decision rules. contingency pians, and monitoring plans to efficiently design the remedy and to prevent implementation failures by responding to actual field conditions. These tield conditions will vary trom the probable conditions that are used to base the RI/FS and remedy seiection. SAFER streamines the RD/RA by providing a tramework to manage uncertainty during the RD/RA through the use of modifying the remedy as new information is gained according to pre-pianned contingency plans that were developed by the extended project team.

One essential element of SAFER is to "learn-as-you-go." As described in Submodule 7.1 and illustrated in Submodule 7.2. SAFER allows for efficient incorporation of new information. This is oniy possible by carefully deveioping pians of action. Note the effor spent in Scoping an RI/FS (see Module 1) to ensure careful and efficient use of resources. Only with careful planning can new intormation be efficiently and effectively incorporated. thus providing the ability to take aggressive yet responsible action.

In a broad sense, the Scoping/RI/FS phase is the planning phase for the RD/RA. As such. all of SAFER's concepts have been introduced and considered before the stan of the RD/RA, aithough not developed to the same level of detail. For example, a comprehensive understanding of probable conditions exists, while only a conceptual understanding of the monitoring plan has been developed.

As a resuit of the planning of Scoping/RI/FS. the extended project team and other stakeholders have agreed to a remedy and how remaining uncertainties will be managed during RD/RA. To a large extent, the $\mathrm{RD} / \mathrm{RA}$ phase is the implementation of these plans. The RD/RA is streamlined because the approach and decisions have been proactively addressed.

This document (i.e., Modules 1 through 8) provides detailed guidance on the RI/FS and Remedy Selection process. Submodule 7.3 provides an overview of SAFER concepts during the RD/RA. Although not part of this document. SAFER RD/RA concepts are included to provide a complete presentation of SAFER in the CERCLA process. Detailed RD/RA guidance that incorporates SAFER concepts is forthcoming from DOE. Currently available RD/RA guidance is reterenced in Moduie 7 Sources.

\section{Organization}

Submodule 7.3 discusses the following:

- Probable Conditions

- Deviations

- Decision Rules

- Contingency Plans

- Monitoring Plans

In addition, more detailed information is provided in the following notes:

- Note A-Contingency Plan Checklist

- Note B-Monitoring Plan Checkist

Submodule 7.3 SAFER During Remedial Design and Remedial Action 


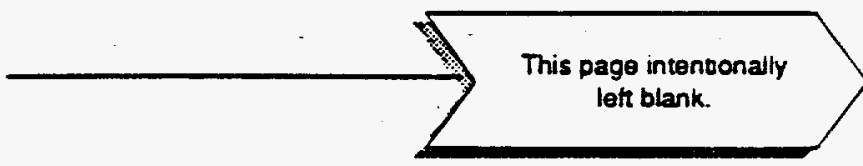

7.40

B. 40 


\section{Probable Conditions}

Probable conditions were rully developed during the Scoping/RI/FS phase. The probable conditions continue to provide the project's focus during the RD/RA phase. They are the basis for the RD and the staring point for the RA.

Remedial Design. Probable conditions. used as the basis for detailed design, are the same conditions that result from the Scoping/RI/FS phase. Limited design data gathering effors may be necessary to supporn detailed design. The probabie conditions are then revised on the basis of new information.

The remedy is designed to meet or accommodate the probable conditions - those conditions that are expected in the field. Normal engineering safety tactors are part of the design based on probable conditions. Designing for probable conditions streamlines the RD by not forcing the design to "worst case" conditions. thus preventing overdesign of the remedy.

The conceptual model reflects the curtent understanding of probable conditions and provides an effective tool for communicating the intent and effect of design details to the extended project team.

Remedial Action. During RA. the probable conditions are the conditions that are expected. Acnual conditions will vary trom the probabie conditions as they are defined at the start of the RA. Information that results from the RA will revise the probable conditions.

The extended project team interprets the new information and revise the understanding of probable conditions.

The RA transtorms the conceptual model into reality as actual field conditions are identinied.

\section{Deviations}

Deviations have been fully considered and developed during the Scoping/RI/FS phase to determine reasonable deviations. The RD/RA addresses the uncerainty represented by the reasonable deviations.

Remedial Design. During RD reasonable deviations provide the basis tor the following:

- A monitoring plan to detect the deviation

- A contingency plan to modify the remedy if a deviation is detected

The RD is streamiined because reasonable deviations are not addressed as part of the detailed design. Contingency plans are prepared to respond to reasonable deviations.

As specific details of the actual remedy are finalized. the deviations should be reevaluated for their technology-based reasonableness. For example, the incinerator specified in the detailed design may differ from the process option defined in the detailed alternative. Each process option responds differently to deviations. Similarly, if design investigations have provided new site information. the deviations should be reevaluated for reasonableness on the basis of the new site understanding.

Submodule 7.3 SAFER During Remedial Design and Remedial Action (continued) 


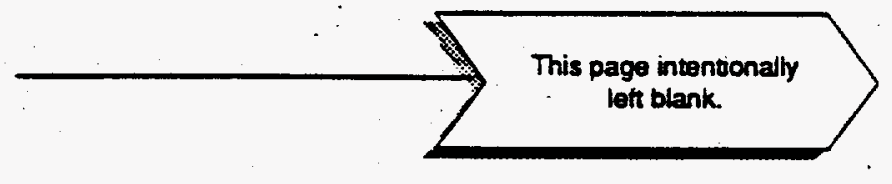

$7-42$

B. 42 
Submodule 7.3 SAFER During Remedial Design and Remedial Action (continued)

As a result of information gained from a design investigation and the detailed RD. the extended project team will determine whether deviations are still reasonable

Remedial Action. Deviations are only detected during the RA. During the RA new information is monitored and evaiuated. Revised understanding of actual tield conditions will result as pan of the evaluation process. Actual field conditions that vary trom probable conditions are deviations: deviations that were determined to be reasonable during the Scoping/RI/FS phase are managed by implementing contingency pians. The extended project team and other stakeholders have previousiy approved of the contingency pians and should be informed of the need to use them.

Actual field conditions that vary from probable conditions and were not prepared for must be evaluared for their impact on the remedy. The extended project team will detemine the required course of action. The conceptual model is revised to retlect the new understanding of the waste site.

\section{Decision Rules}

Two types of decision rules were identitied as a result of the Scoping/RI/FS phase-remediation decision rules and monitoring decision rules. The remediation decision rule specifies the data measurement system criteria for determining that the remediation is complete. The monitoring decision ruie will specify data requirements for detecting specific deviations and link those to specific contingency plans (i.e., a decision rule for each deviation that has a contingency plan).

The remediation decision rule was formally established as part of the ROD. In essence. it defines the restoration goal. The remediation decision rule cannot be modified without altering a legally binding document.

Monitoring decision rules were defined conceptually during the Scoping/RI/FS phase and are not part of the ROD.

During RD/RA the decision rules define the data measurement system that is used for deciding when remediation is complete and what contungency pian to implement when deviations are detected. Data quality and data quantity are directly correiated to the uncerainty that the extended project team teels is acceptable in making decisions of whether remediation is complete or deviation has occurred.

Decision rules focus RD/RA data collection during monitoring of the remedy.

Remedial Design. During the RD, the roie of the remediation decision ruie is to suppon developmeat of the dara measurement system that will be part of the monitoring system.

Understanding of the data measurement system for identifying deviations becomes more detailed as the remedies' specific process options are detailed during RD. The FS evaluations will have involved correlation of contingency plans to reasonable deviations. During RD. one of the primary roles of the extended project team is to define the data collection requirements of the decision rule. This is determined by the level of uncertainty that is acceptable to the extended project team in deciding the necessity of implementing a contingency pian.

Submodule 7.3. Note B. provides additional information on consideration of monitoring parameters to identify deviations.

Submodule 7.3 SAFER During Remedial Design and Remedial Action (continued) 


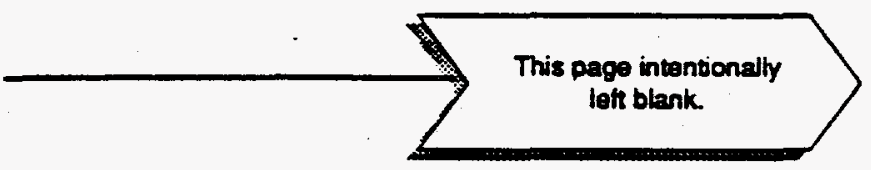

$7-44$

B. 44 
Submodule 7.3 SAFER During Remedial Design and Remedial Action (continued)

Remedial Action. The remediation and monitoring decision rules are implemented through the monitoring system during the RA. These decision rules may require revision to the extent that new information results from the RA. If stakeholders determine that the remediation decision rule requires revision. a modification of the ROD may be required.

\section{Contingency Plans}

Contingency plans were developed to a conceptual level during the Scoping/RI/FS phase. Contingency plans streamline the RD/RA by providing pre-pianned and pre-approved courses of action in the event that a deviation to probable conditions occurs. The need to stop implementing the remedy is minimized while decisions are made about what is necessary to correct the deviation.

Remedial Design. Contingency plans are defined in detail sutficient to manage the reasonable deviations during implementation of the remedy. Detailed consideration of the contingency plans is possible only during the RD because design details are now specinied on the basis of probable conditions. The level of design that is necessary for contingency plans was addressed conceptually during FS. This is now revised on the basis of specific remedy design details. On the basis of probable conditions, the extended project team conducts this evaluation to determine which contingency plans will be included with the design in contract bid documents. The extended project team aiso determines the necessary level of design for contingency not inciuded in the contract bid documents. Submodule 7.2. Note B. provides additional information on contingency plan evaluation criteria.

During the RD. the contingency plans shouid be developed to include a complete strategy to smoothly implement a modification to the remedy. Submodule 7.3. Note A. provides a strategy checklist for contingency plan development.

Remedial Action. Contingency plans are implemented as decision rules specifically during the RA. Minor modifications to contingency plans probably will be necessary as actual field conditions are discovered that differ from the probable conditions and from the reasonable deviations as they are conceptually defined. The extended project team and other stakeholders expect that these minor modifications are necessary.

Although uniikely because of the screening process. actual fieid conditions could result in unreasonable deviations from the expected probable conditions. Because they were identified as unreasonable deviations. no contingency plan was prepared to modify the remedy. However, the SAFER process of integrating stakeholders and constantly revising the approach on the basis of new information provides a framework for reacting to the unexpected field conditions in a controlled manner.

\section{Monitoring Plan}

The monitoring plan was developed conceptually during the Scoping/RI/FS phase.

Upon implementation, the monitoring plan is a monitoring system. Monitoring system requirements are defined by the remediation decision rules and the monitoring decision rules. The decision rules provide a basis for a focused monitoring system. which results in collecting information that is relevant only to the RA. The monitoring system is the data measurement system for the RD/RA. 


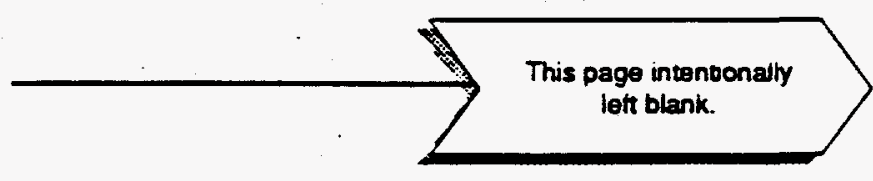

B. 46 
Submodule 7.3 SAFER During Remedial Design and Remedial Action (continued)

Remedial Design. The monitoring system is defined in detail during the RD. The monitoring system will be specified to a sufficient level so that a contractor can implement it. It will be inciuded as part of the construction bid documents. Submodule 7.3. Note B. provides additional detail on monitoring systems.

Remedial Action. Monitoring for deviations begins during construction. as described in the monitoring plan. Monitoring system pertormance begins when construction of a remedial technology (e.g., a cap, incinerator. or groundwater extraction and treatment) begins. Sampling to prove cleanup efficacy may occur during operation of a remedy (e.g., pump and treat. excavation) or may be conducted after construction is complete (e.g., cap). 


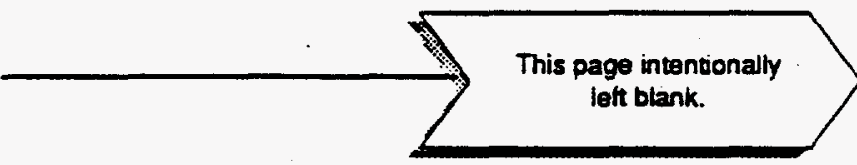

$7-48$

B. 48 


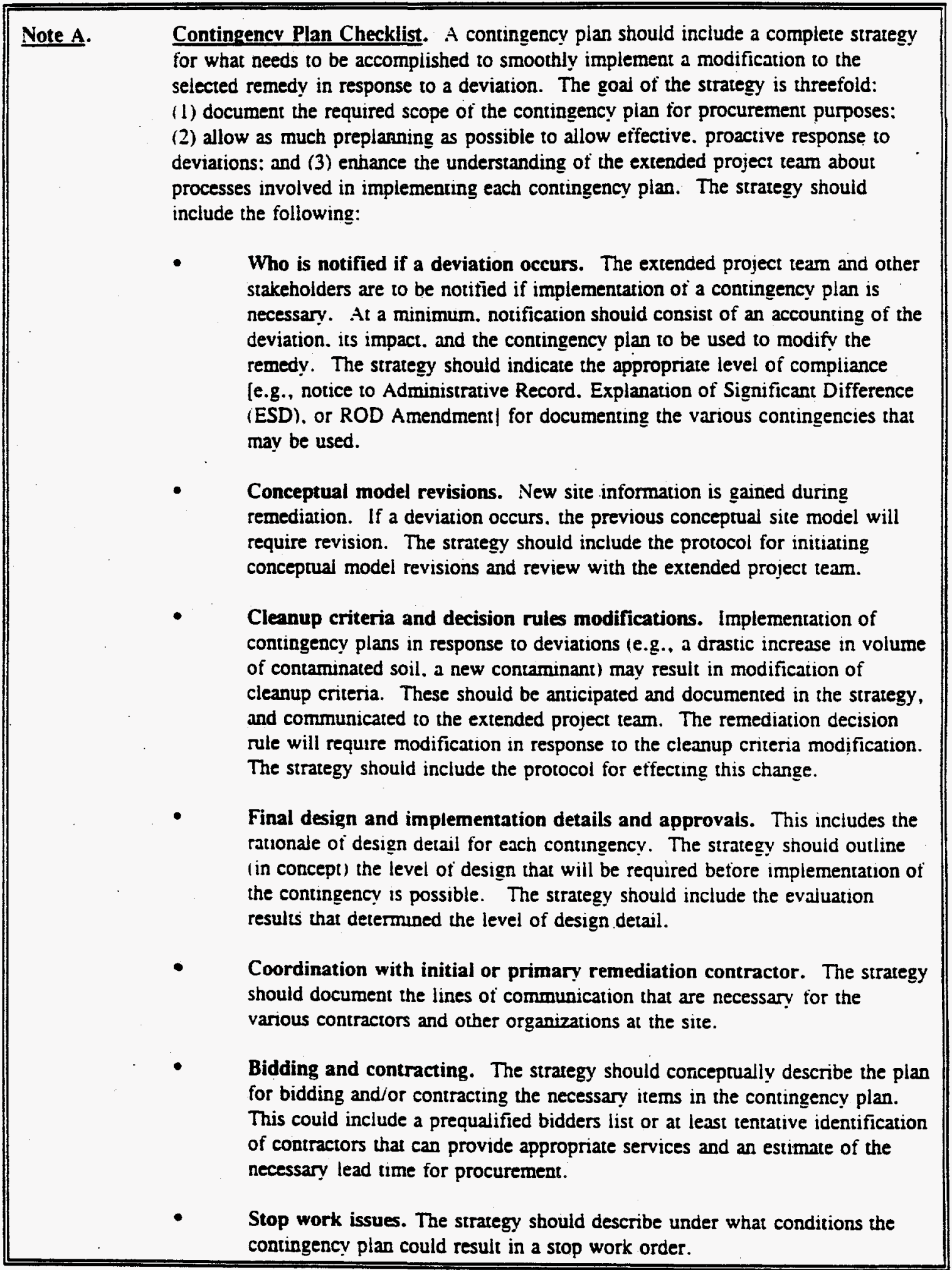




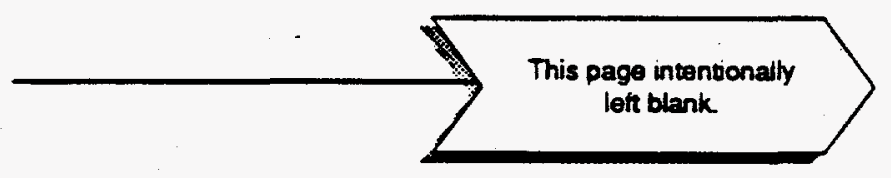

B. 50 


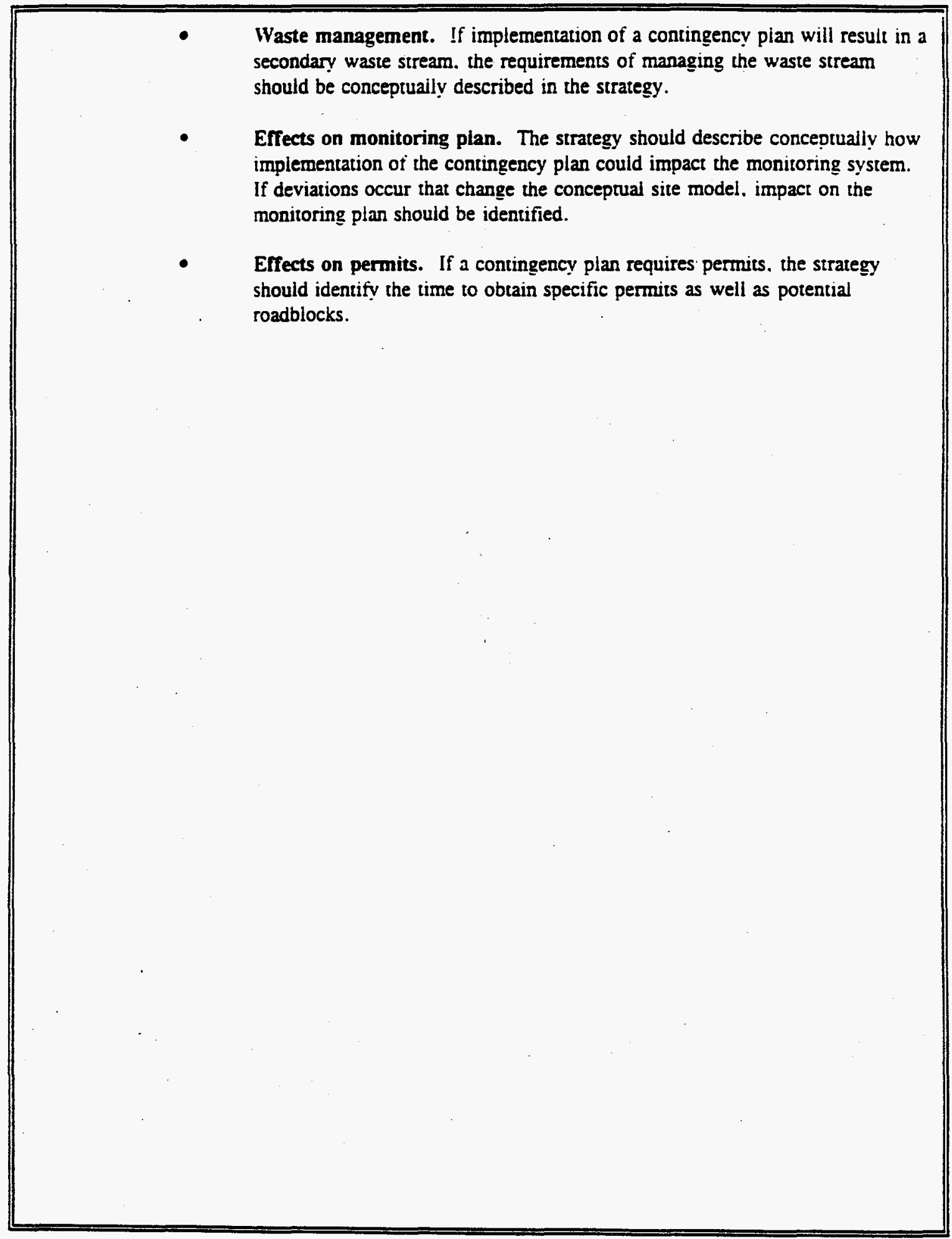

Note A: Contingency Plan Checklist (continued) 


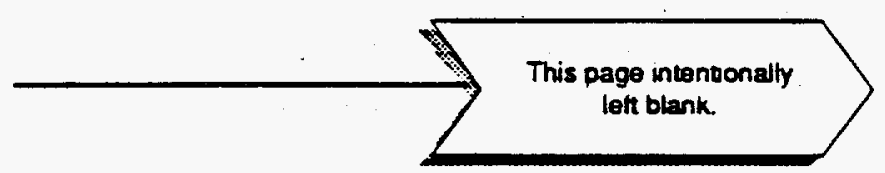

7.52

B. 52 


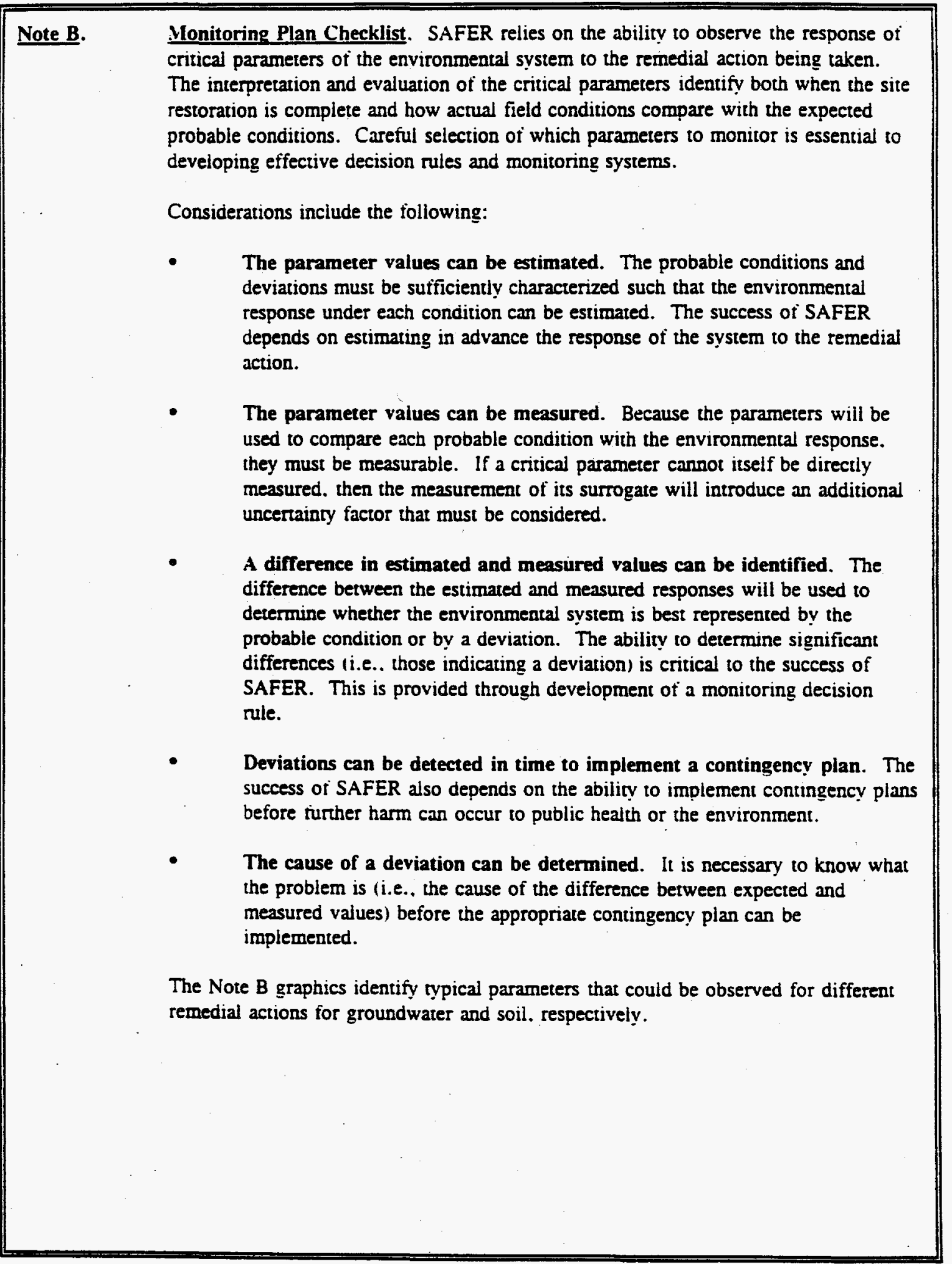

Note B: Monitoring Plan Checklist 
Submodule 7.3 Notes on SAFER During RD/RA

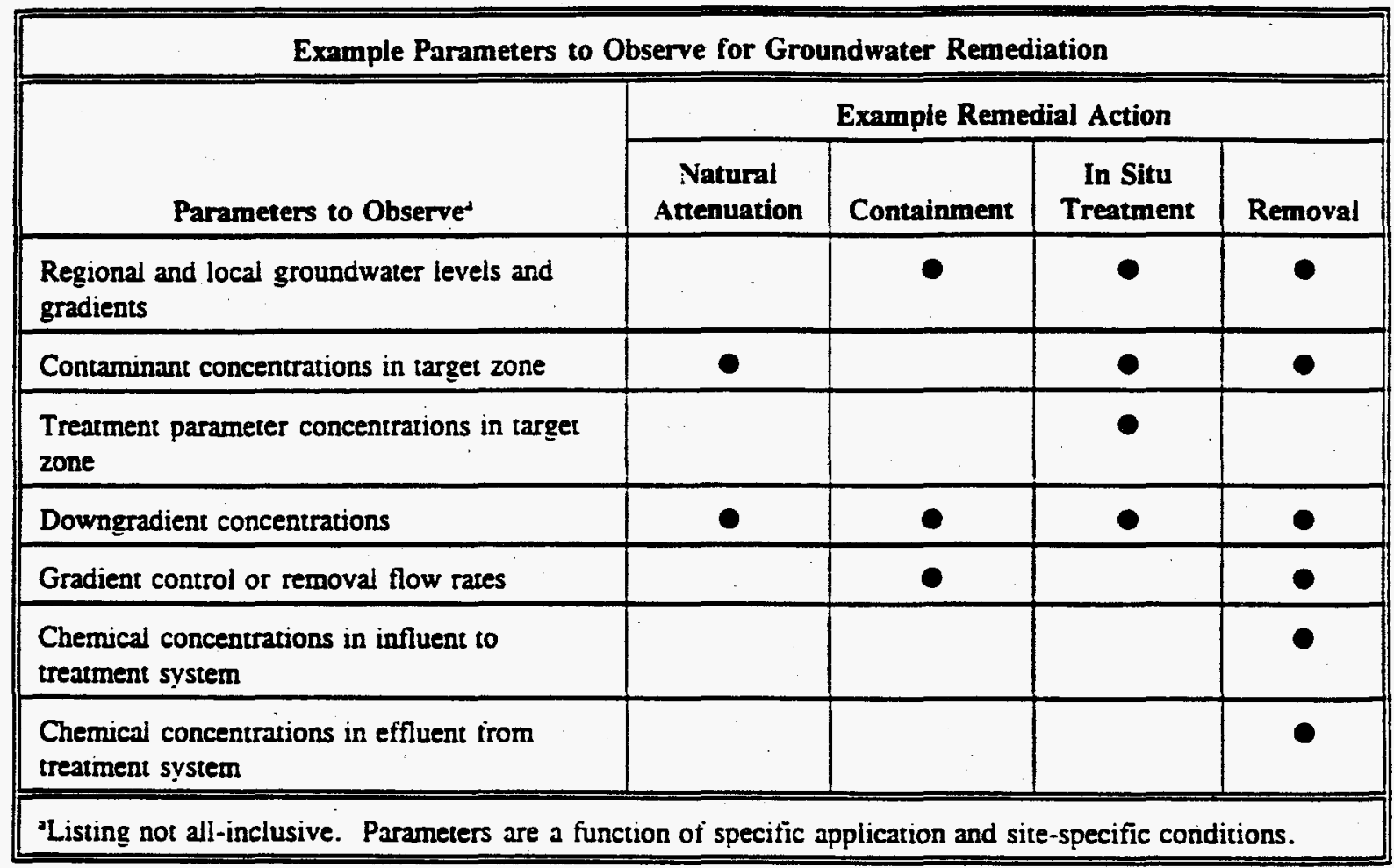

Note B: Monitoring Plan Checklist (continued)

7-54 
Example Parameters to Observe for Soll Remediation

\begin{tabular}{|c|c|c|c|c|c|c|}
\hline \multirow[b]{3}{*}{ Parameters to Observe" } & amiple Parameters to & Observe for $\mathbf{S}$ & II Remediation & & & \\
\hline & \multicolumn{6}{|c|}{ Exnmple Remedial Action" } \\
\hline & $\begin{array}{c}\text { Flushing by } \\
\text { Natural Recharge } \\
\end{array}$ & $\begin{array}{c}\text { Accelerated } \\
\text { Flushing } \\
\end{array}$ & $\begin{array}{c}\text { In Silu } \\
\text { Hloreniedialion }\end{array}$ & $\begin{array}{l}\text { Soil Vapor } \\
\text { Extraction } \\
\end{array}$ & $\begin{array}{c}\text { Air } \\
\text { Sparging } \\
\end{array}$ & $\begin{array}{c}\text { In Sitn } \\
\text { Stabillization }\end{array}$ \\
\hline $\begin{array}{l}\text { Concentrations in soil after periods of treatment } \\
\text { or natural recharge }\end{array}$ & $\bullet$ & $\bullet$ & - & $\bullet$ & $\bullet$ & $\bullet$ \\
\hline $\begin{array}{l}\text { Regional and local groundwater levels and } \\
\text { gradients }\end{array}$ & & $\bullet$ & & & $\bullet$ & - \\
\hline Downgradient ground water concentrations & $\bullet$ & - & - & - & $\bullet$ & $\bullet$ \\
\hline Soil vapor concentrations in target zone & & & & $\bullet$ & $\bullet$ & \\
\hline Pressures/vacuums in targel zone & & & & 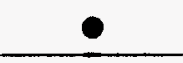 & $\bullet$ & \\
\hline $\begin{array}{l}\text { Oxygen (DO and } \mathrm{O}_{2} \text { ) concentrations in target } \\
\text { zone }\end{array}$ & & & - & & - & \\
\hline Nutrient concentrations in target zone & & & - & & & \\
\hline Regional soil vapor concentrations & $\bullet$ & & $\bullet$ & $\bullet$ & - & \\
\hline
\end{tabular}




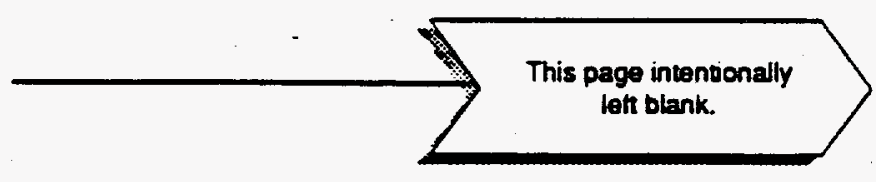

B. 56 


\section{DISTRIBUTION}

No. of

Copies

OFFSITE

12 DOE/Office of Scientific and Technical Information

2 Bartlesville Project Office P.0. Box 1395

$220 \mathrm{~N}$. Virginia

Bartlesville, OK 74005

ATTN: A. Crawley

T. Wesson

E. Bean

Kansas City Area Office

P.0. Box 410202

Kansas City, M0 64141-0202

J. Bellows

Los Al amos Area Office

528 35th St.

Los Alamos, NM 87544

S. Blacker

MACTEC

8310 Centerbrook Place

Alexandria, VA 22308

3 Bonneville Power

Administration

P.0. Box 3621

Portland, OR 97208

ATTN: A. Morrell

S. Sander

B. Sherer

John Cochran

Sandia National Labs

Albuquerque, NM 87115
No. of

Copies

Jack Craig

FEMP

P.0. Box 398704

Cincinnati, $\mathrm{OH} \quad 45239-8704$

5 S. J. Gianti

$\mathrm{CH}_{2} \mathrm{M} \mathrm{Hi} 11$

P.0. Box 4400

Reston, VA 22090

K. Hull

MACTEC

8418 Zuni Rd., SE

Albuquerque, NM 87108

W. Jamison

U.S. Department of Energy

Western Area Power

Administration

P.0. Box 3402

Golden, CO 80401

G. Johnson

Pinellas Area Office

P.0. Box 2900

Largo, FL 34649

B. Kaiser

U.S. Department of Energy

Nevada Operations Office

Yucca Mountain Project Office

P.0. Box 98518

Las Vegas, NV 89193-8518

J. Keller

Naval Petroleum Reserves in California

P.0. Box 11

Tupman, CA 93276 
No. of

Copies

M. Keller

Pittsburgh Energy Technology Center.

P.0. Box 10940

Pittsburgh, PA 15236-0940

D. McCol lum

Morgantown Energy Technology Center

P.0. Box 880

3610 Collins Ferry Rd.

Morgantown, WV 26507-0880

W. R. Miller

Morgantown Energy Technology Center

P.0. Box 880

3610 Collins Ferry Road

Morgantown, WV 26507-0880

J. Morley

U.S. Department of Energy

Dayton Area Office

P.0. Box 66

Mearnesburg, $\mathrm{OH} \quad$ 45342-0066

D. Neptune

Neptune and Company, Inc.

P. 0. Box 10

Los A1 amos, NM 87544

D. Newquist

Naval Petroleum Reserves in California

800 Werner Ct, Suite 342

Casper, WY 82601

P. Ramey

U.S. Department of Energy

Amarillo Area Office

P.0. Box 30030

Amari110, TX 79120-0030
No. of

Copies

Remedial Action Program

Information Center

Building 200

P.0. Box 2008

Oak Ridge, TN 37831-6050

R. Rivera

SCG Inc.

PO Box 5837

Oak Ridge, TN 37831-5837

A. Seepo

Schenectady Naval Reactors Office

P.0. Box 1069

Schenectady, NY 12301

E. Sholl lenberger

Pittsburgh Naval Reactors Office

P.0. Box 109

W. Mifflin, PA 15122-0109

5 J. D. Smyth

$\mathrm{CH}_{2} \mathrm{M} \mathrm{Hill}$

1933 Jadwin, Suite 225

Richland, WA 99352

L. Soholt

Los Alamos National Laboratory

P. 0. Box 1665

Los Alamos, NM 87545

2 Southwestern Power

Administration

P.0. Box 1619

Tulsa, OK 74101

ATTN: D. Hayes

J. Lloyd

Strategic Petroleum Reserve Project Office

Project Management Office

900 Commerce Road E.

New Orleans, LA 70123 
No. of

Copies

U.S. Department of Energy 1000 Independence Ave. Washington, DC 20585

ATTN:
No. of

Copies

C. Billups, EH-8.2

D. Bottre 11, EM-56

C. Bradley, NE-33

S. Brocoum, RW-22

J. Coleman, EM-35

S. Cowan, EM-30

R. Dailey, EH-231

H. Delaplane, FE-421

W. Dennison, GC-11

G. Dicerbo, EH-231

J. Disbrow, EI-531

C. Ebbecke, NP-20

R. Englehart, NP-50

J. Farley, ER-8.2

J. Fiore, EM-42

J. Fisher, $\mathrm{CP}-40$

R. Fleming, EM-431

J. Ford, DP-63

B. Fortune, EH-231

C. Frank, EM-2

M. Frei, EM-34

R. Gisch, NE-60

K. Goodwin, DP-161

C. Halsted, DP-13

S. Hanna, PA-3

L. Harmon, EM-53

D. Isbe11, EM-431

D. Jewett, FE-222

R. Jones, EH-41

A. Joseph, ER-40

J. Knight, DP-12

R. Langum, EM-431

R. Lightner, EM-45

D. Lillian, EM-56

J. Longton, CR-14

J. Lyt le, EM-30

C. Magnuson, EM-431

S. Mann, EM-44

W. Mess, ER-20

R. Moore, EI-23.1

D. Moses, PE-70

H. Myers, CE-64

G. Parker, RW-333

F. Peters, RW-2

R. Peterson, DP-222

H. Pettengi 11 , EH-40

T. Pflaum, DP-3

S. Richardson, DP -60

P. Ritzcovam, NP-52

R. Scott, EM-20

B. Shackleford, EM-33

R. Sharma, NE-47

D. Shelor, RW-30

G. Sherwood, NE-12

D. Silawsky, FE-441

D. Smith, EM-62

K. Sprangle, DP-52

P. Strider, EM-431

D. Swink, FE-4

L. Taylor, EM-43

T. Traceski, EH-231

G. Turi, EM-43

G. Voelker, EM-50

J. Turi, EM-33

R. P. Whitfield, EM-40

W. Wisenbaker, EM-43

F. Wolff, DP-161

R. Wood, ER-74

J. Yates, ER-42

U.S. Department of Energy Albuquerque Operations Office P.0. Box 5400

A1buquerque, NM 87115

ATTN: J. Bickel

K. Bitner

A. Chernoff

D. Krenz

R. Sena

J. Themel is 
No. of

Copies

$2 \quad$ U.S. Department of Energy Albuquerque Operations Office Uranium Mill Tailings Remedial Actions Project Offices

P.0. Box 5400

Albuquerque, NM 87115

ATTN: M. Matthews, Jr. $T$ Plessinger

$3 \quad$ U.S. Department of Energy Chicago Operations Office 9800 South Cass Avenue Chicago, IL 60439

ATTN: B. Fritz

J. Haugen

J. Kennedy

$6 \quad$ U.S. Department of Energy Idaho Operations Office 785 DOE Place

Idaho Falls, ID 83402

ATTN: J. Barry

L. Green

P. Hinman

J. Lyle

W. Sato

J. Zimmerman

$4 \quad$ U.S. Department of Energy Nevada Operations Office P.0. Box 98518

Las Vegas, NV 89193-8518.

ATTN: B. Church

D. Elle

J. Fiore

S. Mellington
No. of

Copies

$6 \quad$ U.S. Department of Energy Oak Ridge Operations Office P.0. Box 2001 Oak Ridge, TN 37831

ATTN: S. Garland (ORNL/ER)

P. Gross

H. Hibbitts

R. Nelson

A. Perkins, MS-6317

R. Sleeman

6

U.S. Department of Energy Rocky Flats Office

P.0. Box 928

Golden, CO 80402-0928

ATTN: S. Grace

J. Hartman

F. Lockhart

T. Lukow

R. Nelson, Jr.

R. Schassburger

4. U.S. Department of Energy

San Francisco Operations Office

1333 Broadway

Oakl and, CA 94612

ATTN: J. Cullen

J. Davis

J. Juettan

M. Kamiya

4

U.S. Department of Energy

Savannah River Operations Office

P.0. Box A

Aiken, SC 29802

ATTN: L. Goidell

T. Heenan

L. Sjostrum

S. Wright 
No. of

Copies

2

U.S. Department of Energy Waste Isolation Pilot Plant Project Office (WIPP)

P.0. Box 3090

Carlsbad, NM 88221

ATTN: A. Hunt

J. Newhinney

B. Vocke

Los Alamos National Laboratory

HSE/D0/ER MS K481

P.0. Box 1665

Los Alamos, NM 87545

R. Waldman

U.S. Department of Energy

Alaska Power Administration

P.0. Box 020050

Juneau, AK 99802-0050

\section{ONSITE}

5 DOE Richland Operations Office

R. M. Carosino, A4-52

R. D. Freeberg, A5-19

R. G. Holt, A5-15

R. D. Izatt, $A 3-42$

L. E. Little, A3-42

2 Westinghouse Hanford Company

M. R. Adams, H6-01

J. G. Woolard, H6-05

$6 \quad$ Battelle Washington Office
J. A. Bradbury
L. A. Corathers
W. E. Fallon
R. E. Hegner
J. D. Longstreth
J. E. Shorett

No. of

Copies

16 Pacific Northwest Laboratory

J. P. Amaya, K8-12

J. G. April, K8-19

G. R. Bilyard, K8-03

C. A. Geffen, K8-09

J. N. Hartley, B1-40

J. F. Keller, K1-21

T. L. Kuusinen, K8-19

T. L. Page, K1-37

B. A. Pulsipher, K7-34

R. D. Quinn, K8-19

Publishing Coordination

Technical Report Files 